\title{
Does Long-Term Care Subsidization Reduce Hospital Admissions and Utilization? ${ }^{\aleph}$
}

\author{
Joan Costa-Font \\ London School of Economics and Political Science (LSE) \& CESifo \\ Sergi Jimenez-Martin \\ Universitat Pompeu Fabra (UPF) \& BGSE \\ and \\ Cristina Vilaplana \\ University of Murcia
}

\footnotetext{
"We are specifically grateful to Edward Norton, Courtney Van Houtven, Judith Vall, Helena Hernández-Pizarro, Jose Luis Fernandez, Alistair McGuire, Andrew Street, R. Tamara Konetzka, Antonio Montañés, and to the participants at the Economics of Integrated Care Conference in London in January 2016, seminars at Pompeu Fabra University, University of Zaragoza, and the Spanish Health Economics Association Meeting 2014 in Pamplona. All have provided very constructive comments and suggestions on earlier versions of this paper. We also thank the Spanish Ministry of Economy, grants ECO2014-52238-R and ECO2014-53419-R, for its financial support, and the LSE for its research support. The authors alone are responsible for any errors, and the usual disclaimer applies.

Contact: Joan Costa-Font, Department of Health Policy, London School of Economics and Political Science (LSE). Houghton Street, WC2A 2AE. Email: j.costa-font@lse.ac.uk
} 


\begin{abstract}
We use quasi-experimental evidence on the expansion of the public subsidization of long-term care in Spain to examine the causal effect a change in caregiving affordability, as regards the caregiving allowance and the reception of home care, on hospital admissions (both on the internal and external margin) and length of stay. We find robust evidence of a reduction in both hospital admission and utilization among both those receiving a caregiving allowance and, albeit less intensely, among beneficiaries of publicly funded home care, which amounts to $11 \%$ of total healthcare costs. These effects were stronger when regions had an operative regional health and social care coordination plan in place. Consistently, a subsequent reduction in the subsidy five years after its implementation is found to significantly attenuate such effects. We investigate a number of potential mechanisms, and show how the effects pass a number of falsification and robustness checks.
\end{abstract}

Keywords: hospital admissions, hospital utilization, long-term care reform, bedblocking, Poisson hurdle model, Spain.

JEL: I18, J14, H53. 


\section{Introduction}

Healthcare systems face the challenge of responding to the rising costs of health care treatments, which are in part driven by an increasingly ageing population. However, part of this rise in the demand for healthcare is said to be due to an inefficient use of health services (especially hospital care) by those patients in need of long-term care (LTC). Such care is often not available because of limited coordination (Mur-Veeman and Govers, 2011; Hofmarcher et al., 2007; Bodenheimer, 2008) and, most commonly, as a result of limited affordability. However, only limited research has so far focused on the identification of an expansion in the access of affordable LTC from quasi-experimental evidence.

We use evidence from a reform that extended the public subsidization of LTC services in Spain from January 2007 (referred to in Spanish as the Sistema de Autonomía y Atención a la Dependencia - SAAD). This unexpected reform both universalized the access to previously means-tested LTC services (to those qualifying after a needs test) and made it more affordable. One of the reform's advantages is that SAAD was heterogeneously implemented in each region (e.g., differences emerged in the stringency of needs tests, diversity in copayment rules, etc.), which allows a reasonable identification of its effects on avoiding hospital admissions at both the intensive and the extensive margin (i.e., the probability of hospitalization and the number of hospital admissions), as well as utilization (i.e., hospital length of stay - LoS). An additional advantage of the estimates from SAAD is that it offers a second experiment to test the reform's robustness in terms of the reduction in the subsidy in 2012 (amid austerity cuts). Finally, given the regional decentralization of the Spanish healthcare system, we have been able to examine the heterogeneous effect of SAAD in regions with pre-existing coordination plans ${ }^{1}$. Finally, given that SAAD provides subsidies both in kind (by extending the network of home healthcare), and in cash (by providing a caregiving allowance), we have been able to examine whether the subsidy exerted heterogonous effects depending on the format.

We draw upon data from the Survey of Health, Ageing and Retirement in Europe 2004-2013, which contains a rich set of time-varying controls, both at individual and regional

\footnotetext{
${ }^{1}$ Prior evidence for Spain suggests that about $68 \%$ of all patients needing social care end up being treated by health services, and care management coordination can bring savings of up to $27 \%$ (Graces et al., 2006).
} 
level. We can use these to measure social and health-related needs ${ }^{2}$. In addition, we have carried out a simple micro-simulation exercise to measure the effect the extension of the LTC subsidy has had on hospital costs. Finally, we have further examined a number of mechanisms that drive our results. Specifically, we describe and test the effect SAAD has on preventing hospital admissions, and specifically on early discharge, thereby reducing LoS. This is important as there were no major reforms in hospital care in the period examined.

Our research extends the previous literature in three ways. First, unlike most previous studies, our estimates are based on quasi-experimental evidence. Second, we examine a number of potential individual-level mechanisms, such as the early detection of symptoms, the prevention of unmet needs (Kemper et al., 2008; Rice et al., 2009), and the provision of a smoother transition of care from hospital to home ${ }^{3}$, income, and housing quality. Third, we can distinguish the effect on hospital admissions and LoS. During the early post-discharge period, defined as the first three to five weeks, approximately $20 \%$ of the oldest patients experience adverse events (Forster et al., 2003) that could lead to readmissions (Naylor et al., 2007). These effects can be significantly improved with additional support, and there is specific evidence to suggest that family caregiving improves patients' reported success after hospital discharge and suitable outpatient medication (Bragstad et al., 2012; Scheurer et al., 2012), and that the use of home care by the vulnerable population may reduce the number of hospitalizations (Konetzka et al., 2012).

Our results suggest that after the implementation of SAAD there is a reduction in hospital admissions (in both the intensive and the extensive margin) and utilization (LoS). We find a higher reduction in the number of hospitalizations among those receiving a caregiving allowance compared to those receiving subsidized home care. Conversely, hospital LoS was shorter among those receiving home care services. Our estimates reveal a greater effect among regions with prior health and social care coordination plans. Finally, we examine certain specific mechanisms driving the effect, such as an increased use of outpatient care, the adoption of housing alterations, or the reduction in perceived loneliness and depressive symptoms.

\footnotetext{
${ }^{2}$ Administrative data do not allow controlling for important socioeconomic characteristics (income and wealth) that are key to understanding the effects of LTC subsidisation.

${ }^{3}$ The availability of formal and informal caregivers may provide some post-acute care at the patient's home, and thus reduce hospital LoS.
} 
The rest of the paper is structured as follows. The next section describes the literature to which the study contributes. Section 3 describes the background and identification strategy. Section 4 contains a description of the data and variables. Section 5 describes the empirical strategy, and section 6 contains the key results on hospital admissions, the explanatory mechanism, and the impact on hospitalization costs. Finally, the paper ends with a discussion section containing its concluding remarks.

\section{Related Literature}

The effect of the introduction of social care programs on hospitalizations has so far provided mixed results. Hospital readmissions, a lower rate of hospital-delayed discharges, and lower emergency readmission rates decline after the introduction of a home visits program (Hendriksen et al., 1984 for Denmark; Sands et al., 2006 and Xu et al., 2010 for the US ; Tomita et al., 2010 for Japan), although other studies find no evidence of this effect (Balaam et al., 1988; Fabacher et al., 1994, and Stuck et al., 1995 for the US; Van Rossum et al., 1993 for the Netherlands; Pathy et al., 1992 and Hermit et al., 2002 for the UK). Receiving informal care decreases the hospital LoS of US Medicare patients following a hip fracture, stroke or heart attack (Picone et al., 2003). Weaver and Weaver (2014) find that the availability of informal care decreases the average LoS at Swiss hospitals by 1.9 days, although it did not affect the probability of hospital admission.

Another set of studies using a methodology closer to ours draws on quasi-experimental data. Rapp et al. (2015) measure the impact of financial assistance for non-medical care on the probability of requiring emergency care among patients with Alzheimer's disease. They conclude that the beneficiaries of LTC subsidies have a significantly lower rate of emergency care than non-beneficiaries. Holmås et al. (2008) have found that a system of penalties for a non-smooth transfer process from hospital to LTC services involved hospital stays that were shorter by approximately 2.3 days. However, the withdrawal of the penalties led to hospital stays that were three days longer. Our study described below seeks to fill some of the gaps in the literature, and as in previous studies it draws upon individual data to study hospital admissions (Norton and van Houtven, 2004; Card et al., 2004; Nielsen, 2016; Geil et al., 1997).

Finally, some of the literature related to our study examines the effect of improvements in integration and care coordination on healthcare use. Health and social care 
coordination is found to improve an individual's quality of life (Hofmarcher et al., 2007), but without a cost increase (Singh and Ham 2005). However, the effects on hospital admission are not always consistent across different programs. We add to this literature by examining a unique reform that extends the subsidization of LTC, and hence also provides an exogenous variation in the access to affordable LTC.

\section{Background and identification}

\subsection{Public Insurance Expansion}

Spain's 'Promotion of Personal Autonomy and Care of Dependent People', Law 39/2006, was passed on December 14, 2006 and enacted in 2007 (we refer to it using its Spanish acronym SAAD). The reform was effectively an unexpected expansion of public funding (the outcome of a last-minute political agreement by different political groups supporting a minority socialist government elected after the 2004 Madrid bombings ${ }^{4}$ ).

Before the introduction of SAAD, the provision of LTC was means-tested and funded by local authorities. Access to different social services (home care, day centers and nursing homes) was conditional upon the score obtained on a rating scale that considered various characteristics (age, disability status, income, and family situation). The weights assigned to each characteristic were different across regions ${ }^{5}$. In turn, the social security system was responsible for some elements of care in the form of cash benefits (major disability benefit, third-party benefits, non-contributory invalidity pensions, family benefits for dependent children) and social services (re-education and rehabilitation).

SAAD defined a universal entitlement to LTC under equal conditions for all elderly people. The entitlement resulted from the following steps: first, subsidy claimants are subject to a 'needs test' and classified into one of the three dependency levels ('moderate', 'severe' or 'major') according to an official ranking scale 6 . Second, an individual's care plan is designed

\footnotetext{
${ }^{4}$ Spain's LTC reforms were introduced by a government formed by a parliament elected three days after the 2004 Madrid bombings (Garcia Montalvo, 2011). The new minority socialist government anticipated an agreement toward the end of 2006 to implement a tax-funded subsidization of the LTC system. It is therefore plausible to assume that the reform was not expected.

${ }^{5}$ IMSERSO (2004).

${ }^{6}$ The Ranking Scale evaluates 47 tasks grouped into ten activities (eating and drinking, control of physical needs, bathing and basic personal care, other personal care, dressing and undressing, maintaining one's health, mobility, moving outside home, and housework). Each task is assigned a different weight, and there is a different scale for individuals with mental illness or cognitive disability. Additionally, the evaluation considers the degree of supervision required to perform each task. The final score is the sum of the weights of the tasks for which the individual has difficulty multiplied by the degree of supervision required. The degree of dependency is determined as the result of the sum: not eligible (less than 25 points), moderate dependent (between 25 and 49
} 
by regional welfare authorities to determine the services and/or benefits that best meet the applicant's own needs and those of their family. Entitlements include a choice between access to subsidized weekly hours of home care ${ }^{7}$ (as well as day and night centers and residential services) and a caregiving allowance. Caregiving allowances are designed to compensate informal caregivers (including social security contributions) under the following circumstances: (i) kinship (up to a third degree of consanguinity), (ii) co-residing with the dependent, and (iii) access to suitable housing conditions. The amount of caregiving allowances for major dependency ranged between $390 € /$ month and $487 € /$ month in 2007 , between $417 €$ and $530 €$ in 2011 and between $387 €$ and $442 €$ in 2013. For severely dependent individuals, the cash allowance was set between $€ 180$ and $€ 300$ in 2011 , and between $€ 236$ and $€ 268$ in 2013. For the moderately dependent: $€ 153$ in 2013 . For a better understanding of the amount of caregiver and disability allowances, they can be compared with Spain's minimum wage of $570.60 € /$ month (2007), $641.40 € /$ month (2011), and $645.30 € /$ month (2013).

Figure 1 describes SAAD's implementation (progressive incorporation of less severe dependency levels, as well as the amount of caregiving allowances).

\section{[Figure 1 about here]}

SAAD introduced a tax-funded entitlement to address the needs of older and dependent people. Funding was partially provided by the central government and matched by regional funds (and individuals are expected to contribute, although they seldom do). Regional governments determine the services provided, the conditions and amount of cash benefits, the criteria for beneficiaries' contributions (copayments), and the scale used to assess dependency. The latter, together with different political priorities, lead to significant heterogeneity both in the initial demographic conditions and in the relative speed of SAAD's implementation (Costa-Font, 2010). Table A1 shows the percentage of population aged 65 and older by region and year (corresponding to the waves of SHARE), which ranges between $10-23 \%$ of the total population. We then estimate regional heterogeneity through an indicator of promptness in individual dependency assessments and the degree of generosity in Table

points), severe dependent (between 50 and 74 points), and major dependent (over 74 points). Royal Decree 504/2007 of April 20 approves the dependency rating scale established by Law 39/2006, of December 14, on the promotion of personal autonomy and attention to people in a dependency situation.

${ }^{7}$ Home care services are provided by professional caregivers, and include those related to household work and personal care. Quality standards are defined, and the professional training required to become a home career is accredited by regional authorities. 
$\mathbf{A 2}^{8}$. We find a high degree of dispersion for both indicators, with a variation of $32-38 \%$ to 100\% (see Table A2). We may therefore conclude that there was a wide variation in the percentage of the population benefiting from the program (e.g., 3.19\% in Andalusia versus $1.17 \%$ per cent in the Canaries, using data for 2010) ${ }^{9}$. Similarly, regions differed in their reliance on caregiving subsidies or in-kind benefits ${ }^{10}$.

Unfortunately, just a year after SAAD was introduced, Spain went into a deep economic recession, which led to spending cuts in healthcare, which we control for as explained in due course. In addition, the recession increased the country's public deficit (8.9\% at the beginning of 2012), and led to a series of spending cuts that included delays in SAAD entitlements in July 2012 (Royal Decree 20/2012, July 13, 2012). Specifically, the subsidy for 'moderate dependency' was delayed until 2015; hence, only those with severe and major dependency were supported. Among these, support for home care fell from 70-90 hours/month to 56-70 hours/month for individuals with major dependency, and from 40-55 hours/month to 31-45 hours/month for those with severe dependency. Finally, caregiving allowances were reduced by between 15 and $25 \%$, conditional upon the degree of dependency, and the Social Security stopped paying social contributions for informal caregivers.

\subsection{Coordination between healthcare and LTC services}

One of the important consequences of the extension of public subsidization (SAAD) was the activation of the pre-existing coordination programs between healthcare and LTC services. Evidence from Spain provides important insights on the effect of health and social care coordination. Traditionally, coordination between health and social care has been limited. One of the traditional reasons for such limited coordination is the asymmetric jurisdictional functional allocation. Social care has traditionally been a local responsibility, which is subject to needs/means testing, while healthcare is run by the regional governments, and is free at the point of need, with the exception of pharmaceutical co-payments.

\footnotetext{
${ }^{8}$ We use official data from the Ministry of Health, Social Services and Equality to examine the number of applications, assessments and people awarded LTC subsidies, and we have computed the ratio between assessments and applications and the ratio between people awarded LTC benefits and assessments across regions.

9 Beneficiaries with respect to the population aged 18 and over. We have used this threshold given the differences in the Ranking Scale between the population under and over the age of 18.

${ }^{10}$ The latter lead to a wide dispersion rate in the cost per dependent (e.g., $€ 5,093$ in the Murcia region versus $€ 12,715$ in the Madrid region), while the percentages of informal caregivers' benefits with respect to total benefits awarded were $68.7 \%$ and $18.6 \%$, respectively; Barriga Martí et al. (2015).
} 
The other main reason for limited coordination lies in the chronic underfunding of social care. Hence, for a reform to exert an influence in the health system it should not only coordinate health and social care by making use of different policies, such as a joint commissioning mechanism, but also expand the funding of underfunded social care. Table 1 reports the health and social care coordination plans in several Spanish regions. However, as we argue, the benefits of health and social care coordination only materialized when the underfunding was corrected. ${ }^{11}$

\section{[Insert Table 1 about here]}

Based on the above description, our research analyzes the following effects (i) SAAD's implementation on the probability of hospital admission (external margin), the number of hospitalizations in the last year (internal margin), as well as total hospital LoS, (ii) the health and social care coordination plans in some regions, and (iii) the reduction in the subsidy after the 2012 austerity cuts.

\section{Data}

In line with other studies examining hospital care use (Norton and van Houtven, 2004; Card et al. 2004; Nielsen, 2016; Geil et al, 1997), we use individual data from the Survey of Health, Ageing and Retirement in Europe (SHARE) for Wave 1 (2004), Wave 2 (2006/2007), Wave 4 (2011) and Wave 5 (2013) ${ }^{12}$. Individual survey data are especially important given that administrative data often lack the wealth of specific individual control for the socioeconomic and demographic characteristics available in survey data. SHARE is the European equivalent of the Health and Retirement Survey ${ }^{13}$, a panel dataset of interviewees born in 1960 or earlier and their partners, covering a number of European countries ${ }^{14}$. SHARE $^{15}$ is the most comprehensive dataset available across Europe for examining the effects of changes in LTC subsidies among the elderly.

\footnotetext{
${ }^{11}$ For the case of Catalonia, Vargas and Vázquez (2007) have found evidence of a scarcity of coordination mechanisms and the preponderance of intra-class efficiency incentives without taking into consideration the most cost-effective treatment in the continuum of care.

${ }^{12}$ Unfortunately, Wave 3 could not be included as it was not comparable with the other waves.

${ }^{13}$ We have not used data from Wave 6 of SHARE corresponding to 2015 because Royal Decree 20/2012 determined that individuals qualified as moderately dependent since the entry into fore would have to wait until July 2015 to receive any cash or in-kind benefit.

${ }^{14}$ Countries included: Austria, Germany, Sweden, the Netherlands, Spain, Italy, France, Denmark, Greece, Switzerland, Belgium, Israel, the Czech Republic, Poland, and Ireland.

${ }^{15}$ SHARE data collection has been funded primarily by the European Commission through FP5 (QLK6-CT2001-00360), FP6 (SHARE-I3: RII-CT-2006-062193, COMPARE: CIT5-CT-2005-028857, SHARELIFE: CIT4-CT-2006-028812) and FP7 (SHARE-PREP: No. 211909, SHARE-LEAP: No. 227822, SHARE M4: No.
} 
Using the four waves mentioned before, our initial sample contains 14,854 observations, but we have discarded observations registering the codes "refusal" or "don't know" for the variables 'hospitalized in the last 12 months', 'number of hospitalizations in the last 12 months', or 'total number of nights in hospital in the last 12 months;. Table $\mathbf{A 3}$ shows the regional distribution of the initial sample and the missing values. The final sample is made up of 14,766 observations (2,261 for W1; 2,313 for W2; 3,667 for W4, and 6,525 for W5).

Table A4 shows the final sample's regional distribution for each wave.

\subsection{Dependent variables}

We define three dependent variables:

a) Hospital Admission (extensive margin) $\left(H_{i}\right)$ is a variable that takes the value 0 if the individual has not spent any nights in hospital over the past twelve months, and is equal to 1 if he/she has. It includes stays due to surgery, medical tests, or non-surgical treatments and mental health problems. Hospital admissions do not therefore include stays in LTC facilities or nursing homes.

b) Hospital Utilization (intensive margin) $\left(H N_{i}\right)$ is a count variable taking the value 0 if the individual has not been admitted to hospital over the past twelve months, and a positive value equal to the number of times he/she has been admitted over the past year. Given that the Spanish LTC reform was first introduced in 2007, and hospital admissions are recorded over the twelve months prior to the survey, admissions coded in the 2007 wave may have actually taken place in 2006. To capture the reform's true effect on hospital admissions, we will assume that the pre-reform period covers Waves 1 and 2 (2004, 2006, 2007), ${ }^{16}$ and the post-reform period covers Waves 4 and 5 (2011 and 2013).

c) Hospital Length of Stay $\left(\operatorname{HLOS}_{i}\right)$ is a count variable taking the value 0 if the individual has not spent a single night in hospital over the past twelve months, and a positive value equal to the number of nights he/she has spent in a hospital over the past year (counting all hospital admissions in the last twelve months).

\subsection{Explanatory variables}

261982). Additional funding has been provided by the German Ministry of Education and Research, the U.S. National Institute on Aging (U01_AG09740-13S2, P01_AG005842, P01_AG08291, P30_AG12815, R21_AG025169, Y1-AG-4553-01, IAG_BSR06-11, OGHA_04-064), and from various national funding sources (see www.share-project.org).

${ }^{16}$ For 2007, the interviews were made at the beginning of the year, as they correspond to the 2006-2007 wave. 
The SHARE questionnaire contains information on the respondents' main sociodemographic characteristics that are often not available in many observational studies, such as age, gender, level of education, marital status, self-reported health status, Katz Index ${ }^{17}$, net income (€2011), and net wealth (€2011) (Van Rossum et al., 1993; Rapp et al., 2015). Before SAAD, individuals receiving a caregiving subsidy were identified through the SHARE questionnaire as those belonging to one of the following groups: permanent disability benefit, third-party benefits, non-contributory invalidity pensions or family benefits for dependent children. After 2007, SAAD can only be accessed by either (i) individuals that were not previously receiving any type of benefit (permanent disability benefit, third-party benefits, non-contributory invalidity pensions, family benefits for dependent children), who started the application process and were evaluated according to SAAD's Official Ranking Scale; or (ii) individuals already receiving any one of the benefits listed in the previous point, who were reevaluated according to the Ranking Scale, and re-classified as a moderate, severe or major dependent. Although the law guarantees that the Ranking Scale is valid throughout Spain, the test is carried out by officers working for the region where the applicant resides to determine the services or benefits that best meet the applicant's needs. This means there is significant regional variability, in addition to other differences in the reform's actual implementation.

We define two binary variables: $C B_{i}$ takes the value 1 if the beneficiary receives a caregiving allowance, and zero otherwise. The allowance is paid to the dependent individual to compensate the informal caregiver. $H B_{i}$ takes the value 1 if the beneficiary receives public home care benefit, and zero otherwise. Caregiving allowance and home care benefits are mutually exclusive.

Coordination programs between healthcare and LTC services were heterogeneous across regions. Some regions implemented health and social care coordination plans both before and during the period of analysis. We define a binary variable (Coord) that takes the

\footnotetext{
${ }^{17}$ The Katz Index is not directly provided by SHARE, but has been obtained using data on disabilities for DLAs, following Katz (1983). The dependency degree is approximated using the Katz Index (Katz, 1983). The Katz Index determines functional status as a measurement of the ability to perform six daily living activities independently. We have computed this index using the information on DLAs provided by SHARE. Respondents have been classified into four categories: Katz0 indicates that the individual performs all activities independently; Katz1 indicates that the individual performs four or five activities independently (which could be identified as a moderate degree of dependency); Katz2 indicates that the individual only performs two or three activities independently (severe dependency); Katz3 indicates that the individual needs help for all activities (or all but one), and should therefore be considered a major dependent.
} 
value 1 if the coordination program is in place in the region at the time of the survey (see Table 1 for a description of the regions with coordination programs).

Given that hospital deployment might be explained by resource constraints and demand pressures in the health sector rather than LTC subsidization, we control for hospital infection rates, the number of public hospital beds per 1,000 inhabitants, the degree of satisfaction with public healthcare, per capita public health expenditure (€2011), and the rate of medical complications in hospitals.

\subsection{Imputation of public home care for Wave 4}

Our data contain records of caregiving allowances and support received from public home care services for Waves 1, 2 and 5. However, Wave 4's records contain data solely on the caregiving allowance, as questions concerning public home care were omitted from the questionnaire. However, given that we identify the individual-level information from previous waves, a multiple imputation procedure has been used to deal with missing data (Rubin, 1987). This technique allows predicting what the random missing values would have been using information from the whole dataset (Waves $1,2,4$ and 5$)^{18}$. It requires two main assumptions: (i) the data must be missing at random, which is clearly the case because observations for public home care are missing for all the individuals in Wave 4, and (ii) the reasons for the missing data must be captured by other variables that do not have missing values.

As the missing variable is binary, a logistic imputation method has been chosen, and the following explanatory ${ }^{19}$ variables have been introduced: age, gender, being married, having co-resident children, pathologies (stroke, mental illness, Parkinson's, hip fracture), and a left-wing regional government. To test the sensitivity of our results, we have selected five different random seed values, and added five different imputations to our main dataset. The results in these alternative cases were very similar to the original estimations.

\footnotetext{
18 Kalton (1986) and Lepkowski (1989) review methods for compensating for wave non-response, and recommend cross-wave imputation if there are data from multiple waves.

${ }^{19}$ We have not used 'receiving home care in the previous wave' as an explanatory variable due to the relatively low retention rate between waves. Only around $60 \%$ of the individuals interviewed in one wave continue in the next one (see footnote 37 for more details). Although we do not use the panel information for imputation, we can use the panel structure to obtain an approximate goodness-of-fit measure for the imputation procedure. We find that $88 \%$ of those receiving home care benefits in 2006/2007 that are present in the 2011 wave are identified by the imputation procedure.
} 
We assess the reliability of our imputations by drawing upon official data published by the Ministry of Health, Social Services and Equality ${ }^{20}$. Table A5 shows that the number of home care benefits awarded in June 2011 amounted to 110,586. Two important caveats should be mentioned before comparing these figures with our imputations. First, no official data disaggregated by age and type of benefit are available. We only know that $85.78 \%$ of beneficiaries are aged 46 and over ${ }^{21}$, and we unaware of the number of beneficiaries aged 50 and over receiving public home care. Second, the quality of official data published by the Ministry is conditioned by the reports submitted by the departments of social services in each region or autonomous community, which might explain why some regions do not seem to have awarded any home care benefit. The imputation procedure assigned 180 home care benefits in 2011. Using the calibrated weights provided by SHARE, we find that 103,732 individuals were receiving home care benefit at population level. This means a difference of 6,584 fewer individuals than in the official data. However, based on previous considerations, we assume our imputations to be fairly reliable.

\subsection{Descriptive statistics}

Table A6 provides a comparison between data from SHARE and from the National Health Survey (NHS) for Spain. We have used waves corresponding to 2003, 2006 and 2011 as a comparison method with SHARE data for Waves 1 (2004), 2 (2006/07) and 4 (2011). Unfortunately, the Spanish Institute of Statistics has not recorded any more NHS waves after 2011, and we cannot perform the comparison for Wave 5 of SHARE. Table A5 compares regional data for the percentage of hospitalizations and their number in the last year. The NHS only reports hospital LoS, whereas SHARE registers the LoS of all hospitalizations recorded in the last year. This means it has not been possible to compare both variables. In spite of these limitations, we observe a close similarity between both surveys for the percentage of hospitalizations and their number.

Table A7 in the Appendix provides the descriptive statistics for the number of hospital admissions and hospital LoS. We identify 1,254 out of 14,766 observations corresponding to beneficiaries of LTC benefits, with 751 of those received caregiving allowances $\left(C A_{i}\right)$ and

\footnotetext{
${ }^{20}$ http://www.dependencia.imserso.gob.es/dependencia_01/documentacion/estadisticas/est inf/inf gp/index.htm

${ }^{21}$ The age interval starts at 46 (and not at 50) because it is the only disaggregation available on the web page.
} 
503 receiving home care benefits $\left(H B_{i}\right)$. Furthermore, 355 of them (as well as 1,034 nonbeneficiaries) have been hospitalized. ${ }^{22}$

It is noticeable in almost all the cases that the standard deviation exceeds the mean, which is a clear indication of data overdispersion. Between Waves $1 \& 2$ and Wave 4, hospital LoS has decreased both among those receiving caregiving allowances (from 11.35 to 8.75) and home care (from 15.36 to 11.54). However, and importantly, we find that the previous reduction in hospital LoS partially disappeared between the last two waves, especially among those receiving caregiving allowances (from 8.75 in W4 to 12.09 in W5). Similar conclusions are obtained from the analysis for the number of hospital admissions.

A core assumption of the difference-in-differences strategy we use to identify the model's key parameters is that the time trend is common to both groups. Hence, both treatment and control individuals are expected to record hospital admissions that are the same as without the LTC reform, after controlling for observables. Although this common time trend assumption is not directly testable, it is very plausible in our context based on existing comparable pretrends. Since no other LTC legislation was passed after 2007, we would a priori expect to see a change in the percentage of hospital admissions for the treatment group in the reform year, with like-for-like time trends in subsequent years. This is indeed what we find.

Figure 2 shows the trends in the external margin of our dependent variable, that is, the percentage of hospital admissions by type of LTC support received. Importantly, after 2007 we observe a reduction in the frequency of hospital admissions among both beneficiaries of caregiving allowances and home care, but not among those who do not receive any benefits. Consistently, in 2013, and possibly due to the effect of the austerity cuts in 2012, some of these benefits were reversed. However, a number of other misleading effects need to be controlled for in these trends, and we do so in our econometric analysis below.

\section{[Insert Figure 2 about here]}

Figure 3 shows the density function for hospital LoS distinguishing those benefitting from SAAD and those not doing so at the time of the survey. It is noticeable that SAAD

\footnotetext{
${ }^{22}$ Regarding the number of observations, Forster et al. (2003) have analyzed the incidence of injuries after hospital discharge using a survey of 400 respondents interviewed by telephone, and Seymour and Pringle (1982) have studied the incidence of postoperative morbidity and other socioeconomic and administrative factors using a sample of 1,590 individuals aged 65 and over. Finally, Geil et al. (1997) have analyzed hospital admissions in Germany with a comparable number of observations for general and chronic condition subsamples. Additionally, Schwartz and Giles (2016) have shown that the maximum likelihood estimation of the zero-inflated Poisson model has very little bias, even in relatively small samples.
} 
beneficiaries and non-beneficiaries follow opposite patterns. We find a decrease in LoS among beneficiaries between 2004/07 and 2011. In contrast, we find a shift to the right among non-beneficiaries. Consistently, between 2011 and 2013 the density functions for both groups partially reverse the displacements observed in the previous sub-period (e.g., a higher concentration of a lower $\operatorname{LoS}$ for non-beneficiaries, but an increase for beneficiaries).

\section{[Insert Figure 3 about here]}

Table A8 provides a detailed table of descriptive statistics for individual explanatory variables. Individuals receiving home care benefits are on average 10 years older than the beneficiaries of caregiving allowances. They also record a higher concentration of women, and widowed or more dependent individuals. Regardless of beneficiary status, all the groups have seen a sharp decrease in their real net income and real net wealth between both subperiods.

Table A9 reveals that public health expenditure and the degree of satisfaction with the public healthcare system peaked in 2011. This is a direct effect of the austerity cuts resulting from Royal Decree-Law 16/2012 23 . Second, the number of resources and the quality of care received at hospitals is proxied by the hospital infection rate and complications rate ${ }^{24}$, as well as by the number of public hospital beds per 1,000 inhabitants. We note an increase in the infection rate at hospitals in the last two waves, and a progressive rise in the number of hospital beds per 1,000 inhabitants in publicly owned hospitals during the period. Finally, the rate of hospital complications has increased sharply in the last two waves.

\section{Empirical Strategy}

\subsection{The count nature of hospital admissions}

Given the discrete nature of both the number of hospital admissions and hospital LoS (dependent variables do not have negative values), a linear model is likely to distort the count data generating process, and may lead to negative or non-integer predictions (King, 1988). Although the Poisson specification is the natural candidate for these processes, it might be too restrictive if the variance of the data exceeds its mean (overdispersion). A common alternative

\footnotetext{
${ }^{23}$ Royal Decree-Law 16/2012, of April 20, described urgent measures to guarantee the sustainability of the National Health System, aimed at improving the quality and assurance of care. It changed entitlement to the healthcare system from one based on residence to another based on contributions, and increased the patient costsharing of prescribed medicines (see more details in Gené-Badia et al., (2012); Legido-Quigley et al. (2013)).

${ }^{24}$ The infection and complications rates are considered by the AHRQ (2007) and the ECHI (2013) as quality indicators of healthcare services.
} 
to the Poisson model is the negative binomial model. However, even though the negative binomial solves the problem of overdispersion, neither of them provides a suitable fit if there is a large percentage of zero observations in the dataset.

The approaches normally used in the empirical literature include zero-inflated and double-hurdle specifications. The zero-inflated model is sensitive to the fact that zeros may arise in two circumstances; that is, either as a consequence of a strategic decision, or due to incidental reasons (Winkelmann, 2008). Some individuals may report zero hospital admissions because they have not suffered a serious enough health shock to require admission to a hospital. These individuals may be referred to as 'strategic non-hospitalized'. On the other hand, an individual requiring hospitalization, but not admitted, would qualify as an 'incidental zero observation'. 25

Our preferred alternative is the double-hurdle model, also referred to as the two-part model. The double-hurdle model assumes that 'the zeros' are only the result of strategic decisions, and are hence generated by a mechanism separated from that of non-zeros (Mullahy, 1986; Gurmu, 1998). The first hurdle determines whether the count variable is zero or has a positive realization (i.e., if the individual has been hospitalized at least once in the past 12 months). A positive value indicates that the first hurdle is overcome, and in this case the number of hospital admissions over the last 12 months and the hospital LoS for all hospitalizations (intensive margin) are modelled using a truncated distribution. Both stages are independent, and the first hurdle is usually modelled as a logit distribution, and the second hurdle as a zero-truncated negative binomial or a Poisson (Cameron and Trivedi, 2013). ${ }^{26}$ Our baseline specification relies on does rely on a pooled dataset to avoid a significant reduction

\footnotetext{
${ }^{25}$ Given the nature of the Spanish health system, this situation seems highly improbable in principle. SHARE only provides information on unmet hospitalisation needs for Wave 1: $0.29 \%(0.33 \%)$ of respondents reported not having received surgery or hospital treatment because they could not afford it (it was not available).

${ }^{26}$ The truncated Poisson allows us to solve the overdispersion problem of the simple Poisson model:

$$
\begin{gathered}
H_{i c t}=W_{i t}^{\prime} \Omega+v_{i c t} \\
\operatorname{Var}\left[H_{i c t} \mid \Omega\right]=E\left[H_{i c t} \mid \Omega\right]+E\left[H_{i c t} \mid \Omega\right]\left(e^{W_{i t}^{\prime} \Omega}-E\left[H_{i c t} \mid \Omega\right]\right) \\
E\left[H_{i c t} \mid \Omega\right]=\frac{e^{W_{i t}^{\prime} \Omega}}{1+e^{e^{-W_{i t}^{\prime} \Omega}}} * \frac{e^{W_{i t}^{\prime} \Omega}}{1-e^{e^{-W_{i t}^{\prime} \Omega}}}
\end{gathered}
$$

Where $H_{\text {ict }}$ denotes our model's dependent variable (number of hospital admissions over the last year, LoS of individual $i$ living in region $c$ in year $t), W_{i t}^{\prime}$ includes all the regressors and $v_{i c t}$ is the residual term. Depending on $e^{W_{i t}^{\prime} \Omega}$ and $E\left[H_{i c t} \mid \Omega\right]$, the mean may be higher or lower than the variance, and so it can accommodate situations of overdispersion and underdispersion.
} 
in the number of observations (from 14,766 to 5,647 in the case of panel data). However, we provide panel data estimates for comparative purposes in section 6.2.

\subsection{The empirical specification of the double-hurdle model}

Regarding the specification of the hurdle model, it must answer two questions. First, how could one best identify the way SAAD has affected hospital variables in both the internal and external margin? Second, how should the estimation itself be specified, and more specifically, how should a two-part model be defined in the presence of potentially endogenous covariates? We address the first issue in this subsection, while the second one will be discussed in the following subsection.

To address the first issue, that is, SAAD's effect on hospital admission (at both the intensive and extensive margin) and LoS, we use a difference-in-differences specification. This approach has been widely used to measure the effect of a new policy or to analyze the impact of policy changes (Cameron and Trivedi, 1986; Wooldridge, 2002). The difference-indifferences method is a standard policy evaluation tool that assesses the effect a policy intervention has on a treatment group compared to a control group once this specific policy has been implemented. As our data do not come from a real experiment, the assignment to treatment and control is based on the evidence provided by SHARE. In our model, $S A A D_{i c t}$ is a binary variable representing the treatment group that takes the value 1 for individuals receiving LTC benefits (either caregiving allowances $\left(C A_{i c t}\right)$ or home care benefits $\left(H B_{i c t}\right)$ ). The control group is therefore made up of individuals that were not receiving any type of benefit when the survey was conducted. As regards the second issue, the estimation of the double-hurdle model faces two important challenges, namely, model specification and the existence of potentially endogenous variables. Let us first describe the specification.

The first hurdle determines whether the count variable is zero or has a positive realization, that is, if individual $i$ living in region $c$ has been hospitalized at least once in the past 12 months $\left(H_{i c t}=1\right)$. It may be expressed as the following difference-in-differences regression for the probability of a hospital admission:

$$
\begin{aligned}
& H_{i c t}=\begin{array}{c}
F\left(S A A D_{i c t} \alpha_{1}+P_{O S T_{t} \alpha_{2}+S A A D_{i c t} * P O S T_{t} \alpha_{3}+X_{i c t}^{\prime} \alpha_{4}+}+\right. \\
\left.+H C_{c t}^{\prime} \alpha_{5}+C_{c}+T_{t}+\varepsilon_{i c t}\right)
\end{array} \\
& S A A D_{i c t}=\left\{C A_{i c t} \text { or } H B_{i c t}\right\}
\end{aligned}
$$


where $\mathrm{F}$ denotes a probability function, $\mathrm{POST}_{t}$ is a binary variable taking the value one for Waves 4 and 5, and the value zero for Waves 1 and 2, $X_{i c t}$ refers to the individual characteristics (age, gender, marital status, level of education, self-reported health status, and dependency degree approximated by the Katz Index), and $H C_{c t}$ denotes the characteristics of the regional healthcare sector (public health expenditure per capita in real terms, number of public hospital beds per 1,000 inhabitants, infection rate at hospitals ${ }^{27}$, and satisfaction with the public healthcare system). In addition, $C_{c}$ and $T_{t}$ denote regional and temporal dummy variables, respectively, and $\varepsilon_{i c t}$ is a random error term that also captures individual unobserved characteristics.

The coefficient of $S A A D_{i c t} * P O S T_{t}, \alpha_{3}$, captures the reform's impact. It evaluates whether receiving a benefit after the reform has any differential effect on the probability of hospital admission with respect to the pre-reform period. Although the reform was introduced nationwide, the speed of the introduction varied widely across regions, so identifying the reform's impact implicitly stems from (it is reinforced by) its regional variation.

When the first hurdle is met, that is, when $H_{i c t}=1$, the second hurdle (or count variable), $H_{i c t}^{*}$ (either hospital LoS, HLoS $i c t$, or the exact number of hospital admissions, $\left.H N_{i c t}\right)$, is modelled using a truncated Poisson distribution ${ }^{28}$.

$$
\begin{aligned}
& H_{i c t}^{*}=\begin{array}{c}
G\left(S A A D_{i c t} \beta_{1}+\operatorname{POST}_{t} \beta_{2}+S A A D_{i c t} * P O S T_{t} \beta_{3}+X_{i c t}^{\prime} \beta_{4}+\right. \\
\left.+H C_{c t} \beta_{5}+C_{c}+T_{t}+v_{i c t}\right) \text { if } H_{i c t}=1
\end{array} \\
& H_{i c t}^{*}=\left\{H L o S_{i c t}, H N_{i c t}\right\}
\end{aligned}
$$

where $\mathrm{G}$ denotes a truncated count specification, and $v_{i c t}$ is an error term assumed to be independent of the first-stage error. The coefficient of $S A A D_{i c t} * P O S T_{t} * \beta_{3}$, evaluates whether receiving a benefit after the reform has any differential effect on the number of hospital admissions or hospital LoS compared to the pre-reform period.

\footnotetext{
${ }^{27}$ We have also estimated the model by substituting the infection rate and number of public hospital beds by the rate of medical complications at hospital. The complete set of results is available upon request.

${ }^{28}$ A statistical exploration of the data has led us to consider a logit plus zero-truncated Poisson (double-hurdle) model to solve the overdispersion problem mentioned earlier. The results (available from the authors upon request) point to the same conclusions for the three types of benefits. First, the significance of the overdispersion parameter (alpha) and the comparison of the AIC and BIC statistics for the Poisson and negative binomial models indicate that the negative binomial model fits the data better. Second, the likelihood ratio test between the Poisson and the hurdle Poisson confirms the suitability of a double-hurdle model. Third, the likelihood ratio test between the negative binomial and the hurdle negative binomial rejects the former. Finally, a comparison between both hurdle models rejects the hurdle negative binomial.
} 
Using maximum likelihood to estimate equations (1) and (2) provides consistent and efficient estimations if $S A A D$ and $X_{i c t}^{\prime}$ are exogenous. However, when the unobserved determinants of $S A A D_{i c t}$ are correlated with $\varepsilon_{i c t}$ or $v_{i c t}$, the estimated coefficients are biased. We draw from estimates of a pool sample; panel data estimates are nonetheless provided in section 6.2.

\subsection{Dealing with the endogeneity of SAAD variables}

As noted above, one of the threats to our empirical strategy is the potential endogeneity of SAAD. For example, SAAD has been implemented at a different pace in each region, and some regions may have a significantly higher propensity to award cash benefits, whereas others are more prone to set up a network of home care services. As a result, the error term of (1) or (2) could be correlated with unobservable variables that affect the implementation of SAAD. Hence, assuming that SAAD is exogenous in (1) or (2) may lead to inconsistent estimates of the model's key parameters.

Given the difference-in-differences specification used, we have two potential endogenous variables: $S A A D_{i c t}$ and $S A A D_{i c t} * P O S T_{t}$. We therefore propose using a control function $(\mathrm{CF})$ approach to account for their potential endogeneity. This technique, suggested by both Wooldridge (2002) and Blundell and Powell (2003), is useful for estimating nonlinear models ${ }^{29}$. In a first stage, we run a linear regression of the endogenous variables on all exogenous variables and instruments, and obtain the residuals.

$$
\begin{aligned}
& S A A D_{i c t}=\mathrm{Z}_{i c t}^{\prime} \partial_{1}+X_{i c t}^{\prime} \partial_{2}+H C_{c t}^{\prime} \partial_{3}+C_{c}+T_{t}+\xi_{i c t} \\
& S A A D_{i c t} * P O S T_{t}=\mathrm{Z}_{i c t}^{\prime} \vartheta_{1}+X_{i c t}^{\prime} \vartheta_{2}+H C_{c t}^{\prime} \vartheta_{3}+C_{c}+T_{t}+s_{i c t}
\end{aligned}
$$

where $S A A D_{i c t}$ is either $C B_{i c t}$ (caregiving allowances) or $H B_{i c t}$ (home benefits), $\mathrm{Z}_{i c t}^{\prime}$ is a vector of instruments, and $\xi_{i c t}$ and $\zeta_{i c t}$ are residuals distributed according to $\mathrm{N}(0,1)$. We obtain the first-stage residuals $\left(\hat{r}_{S A A D_{-} i c t}\right.$ and $\left.\hat{r}_{S A A D_{-} P O S T_{-} i c t}\right)$ and, in a second stage, we use them as additional control variables in both hurdles. We use bootstrapping to obtain valid standard errors. The final difference-in-differences double-hurdle model controlling by the potential endogeneity of the LTC variables is given by the following equations:

\footnotetext{
${ }^{29}$ Terza et al. (2008) contend that two-stage least squares estimation may lead to inconsistent estimates, and so the residual inclusion estimation is the preferred approach in non-linear settings.
} 


$$
\begin{gathered}
H_{i c t}=\begin{array}{l}
F\left(S A A D_{i c t} \alpha_{1}+P_{\text {PST }} \alpha_{2}+S A A D_{i c t} * P O S T_{t} \alpha_{3}+X_{i c t}^{\prime} \alpha_{4}+\right. \\
\left.+H C_{c t}^{\prime} \alpha_{5}+\hat{r}_{S A A D_{-} i c t} \alpha_{6}+\hat{r}_{S A A D_{-} P O S T_{-} i c t} \alpha_{7}+C_{c}+T_{t}+\varepsilon_{i c t}^{*}\right)
\end{array} \\
H_{i c t}^{*}=\begin{array}{l}
G\left(S A A D_{i c t} \beta_{1}+P O S T_{t} \beta_{2}+S A A D_{i c t} * P O S T_{t} \beta_{3}+X_{i c t}^{\prime} \beta_{4}+\right. \\
\left.+H C_{c t} \beta_{5}+\hat{r}_{S A A D_{-} i c t} \beta_{6}+\hat{r}_{S A A D_{-} P O S T_{-} i c t} \beta_{7}+C_{c}+T_{t}+v_{i c t}^{*}\right)
\end{array} \\
S A A D_{i c t}=\left\{C A_{i c t} \text { or } H B_{i c t}\right\}, H_{i c t}^{*}=\left\{H L o S_{i c t}, H N_{i c t}\right\}
\end{gathered}
$$

Implementing a significance test on the joint effect of $\hat{r}_{S A A D_{-} i c t}$ and $\hat{r}_{S A A D_{-} P O S T_{-} i c t}$ provides a simple way to test the assumption that SAAD and SAAD*POST are exogenous in the first and second hurdles, respectively. If the effect of $\hat{r}_{S A A D_{-} i c t}$ or $\hat{r}_{S A A D_{-} P O S T_{-} i c t}$ is significant in one or both equations, we can reject the exogeneity of SAAD or SAAD * POST in the corresponding equation ${ }^{30}$.

Regarding the vector of instruments $\left(Z_{i c t}^{\prime}\right)$, we have considered six different ones. The first one refers to the percentage of support for the socialist party in the last general elections $\left(S o c_{c t}\right)$, as the socialist party's manifesto included the development and implementation of a new LTC legislation ${ }^{31}$ (see Table B1). Specifically, given that the reform was the 'star social program' of a newly elected government, and that the regions were co-financing and implementing the reform, political support for the incumbent party at regional level would be expected to make it easier for the regional government to implement. We take advantage of the fact that in Wave 2 we can distinguish between interviews carried out in 2006 and 2007 to assign more exactly the value of the instrumental variable 'percentage of socialist vote' to each observation. The instrument is both theoretically relevant and empirically significant, and after running further analyses we find no reason to believe it impacts on the dependent variable in any other way but through the reform ${ }^{32}$. The second instrument we use refers to the

\footnotetext{
${ }^{30}$ We have also estimated the model including both types of benefits (caregiving allowances and home care benefits) in the same equation, as well as their interactions with the post-reform dummy. This implies that the number of endogenous variables increases from two to four, and so we must include four residual variables in the second-step equations. As Phillips (1983) has shown, an increase in the number of endogenous variables reduces the danger of omitted variable bias, but also reduces the reliability of estimations because the observation-to-parameter ratio becomes smaller. In view of this and the fact that the number of reliable instruments is limited, we have preferred to estimate the effect each type of benefit has separately.

${ }^{31}$ Regions governed by the socialist party would be expected to speed up the implementation of the reform, as some previous research has documented (Costa-Font, 2010).

${ }^{32}$ According to Bacigalupe et al. (2016), there is no evidence of a link between socialist support in a region and a higher investment in public healthcare services, or vice versa, a positive relationship between conservative regions and privatizations of public hospitals (i.e., Andalusia and Extremadura, which are regions with left-wing governments, have experienced a major decrease in healthcare resources between 2008 and 2013 and a moderate increase (Andalusia) or big increase (Extremadura) in privatizations. By contrast, Murcia, which has a right-wing government, has recorded a moderate reduction in public healthcare resources and a decrease in privatized facilities).
} 
interaction between the percentage of the vote for the socialist party and the post-reform period $\left(S_{S c} * P O S T\right)$.

In addition, we include the coverage index of public home care in 2002 and 2000, before the onset of SAAD, to capture the effect of regional differences in the provision of formal care (see Table B2). The fifth instrument we apply refers to the proportion of women outside the labor market, which can be interpreted as a measure of the propensity to provide informal care. Finally, we define a binary variable if the individual lives in a rural area, and zero otherwise. This variable controls for formal care availability and the willingness to apply for formal care in rural areas compared to cities ${ }^{33}$.

Validity of the instruments. The results of the first-stage regressions confirm the validity of our instruments. Regions with higher socialist support have a lower propensity to award a caregiving allowance, but a significant and positive tendency to develop a network of home care support (Table 2). Given that we control for regional fixed effects, we conclude that the differential speeds in SAAD's implementation were influenced by political support for the regional incumbent. The coverage index of public home care in 2000 and 2002 shows a negative association with the probability of receiving a caregiver allowance and a counter effect on home care. By contrast, a higher fraction of women out of the labor force, or a larger fraction of the population living in a rural area are associated with a higher probability of receiving a caregiver allowance, but a lower probability of receiving home care support.

\section{[Insert Table 2 about here]}

\subsection{Coordination and spending cuts}

In addition to obtaining the average effect of SAAD on hospital admissions, we are interested in two additional specification exercises, namely, the effect of coordination plans and the effect of the budget cuts introduced in 2012/2013. We model them by introducing a triple interaction effect in the specification of both hurdles (SAAD*POST*COORD), which can be interpreted as both the effect of coordination and the effect of SAAD.

In the case of budget cuts, we take advantage of the fact that the final wave of SHARE in our analysis refers to a date subsequent to their introduction. Consequently, the triple interaction, $S A A D^{*} P O S T * 2013$ identifies the effect of the spending cuts in 2012 . This

\footnotetext{
${ }^{33}$ Moreno-Colom et al. (2016) state that socio-cultural factors play an important role in the increase in the number of professional formal care providers. These socio-cultural factors, which are much stronger in rural settings, help to explain why the family continues to provide the main group of care providers in the countryside.
} 
term's coefficient can be interpreted as the additional effect of the budget cuts on top of the reform's 2011 effects.

\section{Results}

\subsection{The reform's effect on hospital admissions}

In keeping with previous results, we find evidence of a reduction in hospital admissions (HAs) among those exposed to SAAD. Table 3 reports the results for the key coefficients of the Poisson hurdle model: the probability of an HA (external margin), the number of HAs (internal margin), and the LoS resulting from the introduction of SAAD, both for individuals benefiting from a caregiving allowance and those receiving home care (all the other coefficients are presented for the baseline case in Table C2). Specifically, panel A reports the baseline case for these effects; panel B presents the coordination case emphasizing the effects for those regions that have implemented coordination programs between healthcare and social care, and finally, panel $\mathrm{C}$ presents the analysis of the effect of budgetary cuts implemented in SAAD in 2013. The first-stage residuals are not significant in the first hurdle (logit), but they are in the second one (truncated Poisson). The Hausman test rejects the hypothesis of endogeneity of SAAD and SAAD * POST in the first hurdle, but accepts it for the second one. However, we keep and present the Instrumental Variable (IV) specification for both hurdles 34 .

\section{[Insert Table 3 about here]}

Baseline results. Panel A in Table 3 reports the model's baseline results, with the treatment variable after the reform captured by the interaction SAAD*POST. Our results indicate that, as expected, the reform did indeed reduce HAs in both the internal and external margin, as well as its LoS. Firstly, the probability of HA decreased by 9.5 pp among those receiving caregiving allowances compared to similar beneficiaries in the pre-reform period, but it is not significant for home care beneficiaries. Second, the effect size for the number of hospital admissions and LOS is different for caregiving allowances and home care. Although the coefficient for home care had a greater impact on the LoS, the coefficient of those receiving a caregiving allowance was larger on the number of hospital admissions. Our effect sizes indicate that the $\operatorname{LoS}$ for beneficiaries of caregiving allowances (home care

\footnotetext{
${ }^{34}$ Table $\mathrm{C} 1$ in the Appendix shows the results for the hurdle Poisson model without the control function. Not controlling for the endogeneity of LTC benefits (caregiving allowances and home care benefits) leads to an overestimation of their effects over the number of hospital admissions and hospital LoS for the coordination case and the analysis of budgetary cuts.
} 
beneficiaries) is $0.79(0.70)$ times shorter than that of similar beneficiaries in the pre-reform period. The beneficiaries of caregiving allowances record an increase in the number of HAs (1.13 times more than non-beneficiaries).

Among those receiving home care, we observe that the probability of HA increases by $5.2 \mathrm{pp}$, and LoS is 1.26 times higher than that of non-home care beneficiaries. The interaction term (SAAD*POST) indicates that the number of hospital admissions in the post-reform period is $0.90(0.70)$ times that of a home care beneficiary in the pre-reform period. ${ }^{35} \mathrm{We}$ may therefore conclude that individuals receiving a caregiving allowance recorded a higher reduction in the number of HAs, and that those receiving support for home care record a bigger decrease in the average LoS.

When we examine the effect of all the other controls (see Table C2 in the Appendix for the detailed results of the analysis), we find that the number of public beds per 1,000 inhabitants does not affect HA in either the internal or external margin. A higher infection rate is negatively correlated with the number of HAs and hospital LoS, whilst higher satisfaction with the public healthcare system is only negatively correlated with hospital LoS. In contrast, higher public healthcare expenditure is positively correlated with hospital $\operatorname{LoS}^{36}$.

The role of care coordination. Panel B in Table 3 reports the combined effect of coordination $^{37}$, receiving LTC benefits, and the LTC reform.

The fact that the variable 'coordination' is not significant in the pre-reform period might indicate that the chronic underfunding of LTC services does not allow coordination to deliver its expected effects. The interaction term $S A A D *$ Coordination indicates that (i) the number of HAs for beneficiaries of caregiving allowances in coordinated regions is 1.33 times higher than similar beneficiaries in non-coordinated regions, (ii) the LoS of home care beneficiaries in coordinated regions is 1.42 times that of similar beneficiaries in noncoordinated regions.

\footnotetext{
${ }^{35}$ We have re-estimated the model removing the infection rate and number of public bed hospitals. Instead, we have introduced the complications rate as regards total discharges. The results of the hurdle Poisson model are robust to this change in explanatory variables. [Results available upon request]

${ }^{36}$ The decrease of $€ 154$ (2011) between 2012 and 2013 is therefore associated with an increase in the number of hospitalizations ( 0.31 for cash benefits, 0.29 for home care) and a very a negligible reduction in $\operatorname{LoS}(0.08$ for cash benefits, 0.05 for home care).

${ }^{37}$ In addition, care coordination may entail a wide range of healthcare services, such as psychogeriatric, longstay, rehabilitation, and palliative care, which have not been considered in this paper (IMSERSO, 2011).
} 
The LTC reform has nonetheless been well-received in regions with coordination programs. The probability of HA for beneficiaries has declined compared to the pre-reform period in coordinated regions (11.6 pp. for caregiving allowances, $18.5 \mathrm{pp}$. for home care benefits). Additionally, the number of HAs in coordinated regions is lower than in the prereform period ( 0.86 times lower for caregiving allowances, 0.79 for home care benefits). The LoS for beneficiaries of home care benefits is 0.66 times lower compared to the pre-reform period.

Nonetheless, the coefficient of the triple interaction $S A A D^{*} \operatorname{Coord}^{*} P O S T$ paints a different picture. First, the probability of an HA falls by $11.6 \mathrm{pp}$. among those benefitting from a caregiving allowance, and by $18.5 \mathrm{pp}$ for home care in regions with coordination programs between healthcare and LTC services. We do not find a significant effect of caregiving allowance on hospital LoS, suggesting that coordination effects only reduce LoS among those receiving home care. These results are consistent with previous findings whereby coordination programs were a breeding-ground for the implementation of the reform (SAAD), insofar as they deliver a reduction in the number of HAs and in hospital LoS in the post-reform period. The negative and significant sign of the $S A A D * \operatorname{Coord}{ }^{*} P O S T$ in the postreform period reveals that SAAD may be interpreted as the formation of links between informal caregivers and healthcare professionals in regions with coordination programs. The results suggest that informal caregivers had not been considered part of the organizational models before SAAD.

Overall, the average hospital LoS of patients receiving home care in regions with coordination programs after the reform is 0.67 shorter than that of other patients receiving home care in a region without a coordination program. The number of HAs has been reduced by $0.86(0.79)$ among those receiving a caregiving allowance (home care beneficiaries) in regions with coordination programs after the reform, as compared to the rest. As in the baseline case, the residuals corresponding to the first-stage regression for the four endogenous variables are significant in the second hurdle, but not in the first one.

The effect of the 2012/2013 budgetary cuts. Finally, panel C in Table 3 shows the effects of the austerity cuts introduced between 2012 and 2013. The interaction term SAAD*POST (2011\&2013) indicates that the LoS for receivers of a caregiving allowance (home care) is $0.86(0.87)$ times lower than that of similar beneficiaries in the pre-reform period. Nevertheless, these reductions in HA have been partially compensated by the opposite 
sign effects observed for $S A A D^{*} P O S T^{*} Y E A R$ (2013), affecting both the LoS and the number of HAs, but not the external marginal of an HA consistent with a bed-blocking effect. In fact, we find that the expected LoS of those receiving a caregiving allowance (home care) in 2013 is 1.29 (1.48) longer than that of similar beneficiaries before that year. Finally, we also find that budgetary cuts have had a significant effect on the external marginal of an HA, particularly for those hospitalized at least once in the last year, where we observe a significant increase in the number of admissions (1.16 HAs/year for caregiving allowances; 1.40 HAs/year for home care beneficiaries).

\subsection{Robustness check: panel data estimates}

Thus far, we have made no assumptions on the individual effects, treating them as nuisance parameters, and we have not exploited the panel nature of the survey to avoid a significant reduction in the sample that may eventually be less representative. ${ }^{38}$ However, after imposing the strict exogeneity of the model's covariates, we check the robustness of the result by extending equations (1) and (2), allowing for specific individual effects to estimate a fixed effects logit model ${ }^{39}$ (see Wooldridge, 2010) and a fixed effect truncated Poisson ${ }^{40}$ (Majo and Vas Soest, 2011) to examine admission and utilization, respectively (see Table C3). For home care beneficiaries, the interaction term (SAAD*POST) indicates that the number of hospital admissions (LoS between brackets) in the post-reform period is 0.79 (0.62) times that of a home care beneficiary in the pre-reform period. These effects are therefore stronger than those obtained for the cross-section model $(0.90$ and 0.70 , respectively). Concerning individuals receiving a caregiving allowance, we obtain a similar result: panel data estimations show that the interaction term for the number of HAs (LOS) is $0.71(0.70)$ times lower compared to a beneficiary in the pre-reform period, whereas the

\footnotetext{
${ }^{38}$ More specifically, the sample falls from 14,766 to 5,647, associated with a lower retention of households or individuals that completed one wave conditional upon having answered the previous wave. Sample sizes for Waves 1 and 2 were 2,396 and 2,228, respectively. However, only 1,375 individuals participated in both waves (a retention rate of $61.7 \% \mathrm{http}: / / \mathrm{www}$.share-project.org/data-documentation/sample.html). As regards Wave 4, the percentage participating in previous waves is also around 60\% (Malter and Börsch-Supan, 2013).

${ }^{39}$ As Wooldridge (2010) has noted, the fixed effects logit estimator has the advantage of being consistent regardless of the distribution of unobserved heterogeneity or its relationship with other explanatory variables. The fixed effects logit model is therefore estimated by considering unobserved heterogeneity as a nuisance parameter, and using the standard conditional maximum likelihood estimator (Chamberlain, 1980).

${ }^{40}$ The estimation by conditional maximum likelihood of the fixed effects truncated Poisson model is consistent, and provides several advantages over other alternatives. First, it does not require the specification of the distribution of unobserved heterogeneities and their relationships with the explanatory variables, as in the fixed effects zero-inflated Poisson model. Second, estimations of the random effects zero-inflated Poisson model are not robust in the event of deviations from the assumptions concerning unobserved heterogeneity and the relationship with explanatory variables. This last caveat does not apply to the fixed effects truncated Poisson model.
} 
estimations for the cross-section model were 0.80 (0.79), respectively. Nonetheless, individuals receiving a caregiving allowance (home care) record a bigger reduction in the number of HAs (LoS). The results for the coordination case and the effect of the 2012/2013 budgetary cuts using panel data head in the same direction as those of the cross-section model, which reinforces our previous conclusions.

\subsection{Mechanisms and Falsification Tests}

This section re-examines certain potential channels for addressing the main challenge discussed in this paper, involving closer supervision under affordable caregiving, and help to explain why access to LTC may lead to fewer HAs, consistent with previous studies (Weaver and Weaver, 2014; Sands et al., 2006). We group these mechanisms into four, namely, i) greater use of outpatient care, ii) reduced onset of mental conditions, iii) reduced loneliness, and iv) housing alterations influencing the opportunity costs of hospitalization.

\subsubsection{Use of Outpatient Care}

We examine the effect of higher affordability and access to LTC on general practitioner (GP) visits to test whether there is some degree of substitution of the care that would otherwise be provided in hospital. We define a binary variable 'Has visited GP' that takes the value 1 if the individual has seen or talked to a GP in the last twelve months, and a count variable 'Number of GP visits' for the number of appointments made in that time (see Table D1 for the descriptive statistics). We estimate a logistic model for the probability of having visited a GP, and a truncated Poisson ${ }^{41}$ for the number of GP visits, considering the same explanatory variables as in the model for HAs, and instrumenting SAAD and SAAD*POST as in the previous section. The results shown in Table D2 suggest that the probability of visiting a GP in the last twelve months is not significantly affected by the SAAD reform, but we find that the number of GP visits in the post-reform is 1.07 times fewer than that of an individual receiving an LTC benefit (both caregiving allowance and home care benefit) in the pre-reform period. We estimate an increase of $0.3 \%$ in primary care costs (see Table 4 ; the procedure is explained in the following section).

\subsubsection{Prevention of Mental Disorders}

\footnotetext{
${ }^{41}$ We have followed the same procedure described in footnote 28 to conclude that the best model is the doublehurdle Poisson.
} 
As an alternative mechanism, we evaluate the reform's effect on the prevalence of mental health conditions, which is found to reduce emergency hospitalizations (Guthrie et al., 2016). Specifically, we examine the prevalence of depression and a self-reported preference for being dead (see Table D1 for descriptive statistics). We define a binary variable 'Dead' and another one for being 'Depressed' that take the value one if the individual has reported preferring to be dead or feeling depressed, respectively. We estimate a probit for both variables, using IV for SAAD and SAAD*POST, and observe (see Table D3) that the probability of having suicidal thoughts decreases by 7.9 pp. (5.4 pp.) for beneficiaries of caregiving allowances (home care beneficiaries) in the post-reform period. A similar effect is found for depression (-2.5 pp.), although it is only significant for caregiving allowances).

\subsubsection{Loneliness}

Loneliness can explain a higher prevalence of HAs. Indeed, Molloy et al. (2010) have found evidence to suggest that loneliness increases hospitalizations. This effect can be captured in our dataset by non-clinical dimensions of being in hospital, such as loneliness, which we measure using an IV probit (see Table D1 for descriptive statistics). We find that the probability of living alone decreases by $7.4 \mathrm{pp}$. (2.6 pp.) for beneficiaries of caregiving allowances (home care beneficiaries) in the post-reform period (see Table D3). This effect is, in turn, consistent with the fact that co-residence with the informal caregiver is a prerequisite in Spain for receiving a caregiving allowance.

\subsubsection{Housing Adjustments}

Finally, another mechanism for early hospital discharge refers to the implementation of home adjustments or alterations that are a standard requirement for receiving subsidized home care or caregiving support. The latter can be captured by examining the effect of a binary variable 'Adapted house' if the household has special features catering for people with physical impairments or health problems, and 0 otherwise (see Table D1 for descriptive statistics). We estimate a probit model for the probability of living in an adapted house, including the same explanatory variables as in the previous regression. The probability of living in an adapted house has increased by $0.02 \mathrm{pp}$ for home care beneficiaries after the reform, but it is not significant for those receiving caregiving allowances (see Table D3 for estimation results).

\subsubsection{Income Effects}


A final mechanism involves the impact of SAAD and the probability of individuals making ends meet, and hence reducing resource-based reasons for a hospital admission. As expected, Table D4 shows a reduction in self-reported household financial difficulties among those receiving cash benefits, but the opposite is true among those receiving home care support. It is therefore unlikely that the results are driven by income effects.

\subsubsection{Falsification Tests}

As a falsification test, we estimate SAAD's effect on unrelated types of care, such as the probability of a visit to the dentist or cataract surgery. Consistently, Table D5 does not provide any evidence of an effect in either type of care.

\subsection{Overall hospitalization costs}

As a way of synthesizing our estimates, we have estimated SAAD's economic impact on hospital costs. Accordingly, we have used official data on the average length and average costs of HAs by region and year provided by the Ministry of Health, Social Services and Equality. First, we have computed the average cost per day as the ratio between total hospital cost and average LoS. Second, we have used the calibrated weights provided by SHARE for each wave to obtain the population estimate of the number of beneficiaries of caregiving allowances and home care beneficiaries. Third, we have applied the estimated coefficients to average length data to obtain the estimated hospital LoS (in days). Finally, we have multiplied the estimated hospital LoS by the number of beneficiaries and the average costs per day ${ }^{42}$. The results are shown in Table 4.

\section{[Insert Table 4 about here]}

For a better understanding of the magnitude of the results, Table 4 compares the estimated increase or decrease in hospital costs with the official data for hospital costs. SAAD's implementation has reduced hospital costs by $11.17 \%$, with $4.95 \%$ due to a reduction in hospital admissions and $6.22 \%$ due to a reduction in LoS. Moreover, in the subset of regions with specific coordination programs between healthcare and social services, SAAD has led to a reduction in hospital costs of $5.21 \%: 2.75 \%$ from a reduction in the number of hospital admissions and $2.46 \%$ from a reduction in LoS. Finally, and as expected, the 2012

\footnotetext{
${ }^{42}$ The procedure used to estimate changes in hospitalisation costs is similar to Holmås et al. (2013).
} 
austerity cuts in the LTC subsidy increased costs by 5.67\%, which is slightly more than the savings from coordination plans.

\section{Conclusions}

This paper has drawn on quasi-experimental evidence from the expansion of the financial access to affordable long-term care services on $\mathrm{HA}$ and utilization. More specifically, we examine the effect of SAAD's introduction in 2007 on the probability of hospital admission, number of HAs, and total hospital LoS over the last twelve months. Our results provide suggestive evidence of a reduction in HAs and utilization after the reform, even after controlling for the endogeneity of the reform's implementation, carrying out a number of robustness checks and falsification tests. Unlike previous evidence, this paper draws on a difference-in-differences approach, and hence provides causal estimates to guide policy reform.

We find that the reduction in HAs is greater among individuals receiving caregiving allowances, consistent with the effect of improved supervision and measures for avoiding HA. However, the effect on LoS is stronger amongst those receiving home care support, consistent with an effect on early discharge. These mechanisms have been further tested. Our results show that SAAD has led to an increase in outpatient care and housing adjustments, alongside a reduction in the prevalence of mental health symptoms and loneliness after its implementation. All of these effects are consistent with the different pathways for reducing hospital use reported in the literature, namely, SAAD's effect on improving the supervision of elderly people and reducing preventable hospitalizations.

Another important finding indicates that the effect of the LTC subsidy (SAAD) was stronger among regions with a regional health and social care coordination plan in place, insofar as it provides a solution to the chronic underfunding of LTC. However, our results suggest that a significant fraction of the savings declines with the reduction of the LTC subsidy in 2012. A reduction of the subsidy, by making LTC less affordable, is found to increase the length of stay and the number of hospital admissions. Overall, our preferred estimates suggest that the implementation of the reform decreased hospital costs by $11 \%$.

Our results face two limitations. First, our estimates capture 'hospital admissions', rather than 'avoidable hospitalizations', given that we cannot identify the latter in our data. Second, our data do not identify subsequent readmissions by patients receiving SAAD. Arguably, more patients could be treated if the LoS were shorter, so the estimation of the 
subsequent costs would be conditioned by waiting lists for certain pathologies and the existence of bottlenecks in some internal services at hospitals.

Notwithstanding these constraints, our results suggest that greater access to affordable LTC may reduce both hospital care admissions and utilization. However, the type of LTC service has different effects. These results are important for policy insofar as they suggest that expanding LTC services and support can provide additional savings in the provision of hospital care. Furthermore, access to affordable care can improve care coordination and help to further reduce hospital utilization ${ }^{43}$. Finally, given that our results refer to both those receiving cash and in-kind benefits, they have important policy implications for systems that rely on one or other of them for LTC services and support.

\footnotetext{
${ }^{43}$ Holmås et al. (2013) investigate the effect of fining owners of long-term care institutions that prolong LoS at hospitals in Norway. Surprisingly, the study found that the stay is longer when fines are used, which is interpreted as an example of monetary incentives crowding-out intrinsic motivation.
} 


\section{References}

AHRQ (2007). Guide to patient safety indicators United States. Department of Health and Human Services Agency for Healthcare Research and Quality. http://www.qualityindicators.ahrq.gov/downloads/modules/psi/v31/psi_guide_v31.pdf

Bacigalupe, A., Martín, U., Font, R. (2016). Austeridad y privatización sanitaria en época de crisis: ¿existen diferencias entre las comunidades autónomas? Gaceta Sanitaria 30, 47-51.

Barriga Martí, L., Brezmes Nieto, M.J., García Herrero, G., Ramírez Navarro, J. M. (2015). Evolución interanual de los datos básicos de gestión de la atención a la dependencia y costes y financiación del sistema por Comunidades Autónomas. XIV Dictamen del Observatorio de la Asociación Estatal y de Directores y Gerentes de Servicios Sociales.

Blundell, R., Powell, J. L. (2003). Endogeneity in nonparametric and semiparametric regression models. In Dewatripont, M., Hansen, L., Turnovsky, S. (eds.), Advances in economics and econometrics: theory and applications, vol. II. Cambridge University Press.

Bodenheimer, T. (2008). Coordinating care: a perilous journey through the health care system. New England Journal of Medicine, 358, 1064-70.

Bragstad, L. K., Kirkevold, M., Hofoss, D., Foss, C. (2012). Factors predicting a successful postdischarge outcome for individuals aged 80 years and older. International Journal of Integrated Care 12, http://doi.org/10.5334/ijic.691.

Cameron, C., Trivedi, P. (1986). Econometric models based on count data: comparisons and applications of some estimators and tests. Journal of Applied Econometrics, 1, 29-54.

Cameron, A. C., Trivedi, P. K. (2013). Regression analysis of count data. Cambridge: Cambridge University Press, $2^{\text {nd }}$ edition.

Card, D., Dobkin, C., Maestas, N., (2004). The impact of nearly universal insurance coverage on health care utilization and health: evidence on Medicare. NBER WP No. 10365.

Chamberlain, G. (1980). Analysis of covariance with qualitative data. Review of Economic Studies 47, 225-238

Costa-Font, J. (2010) Devolution, diversity and welfare reform: long-term care in the 'Latin Rim'. Social Policy and Administration, 44 (4), 481-494.

ECHI (2013). Evaluation of the use and impact of the European Community Health Indicators by Member States. Public Health Evaluation and Impact Assessment Consortium. Directorate General for Health and Consumers of the European Commission. 
https://ec.europa.eu/health/sites/health/files/indicators /docs/echi_report_v20131031.pdf

Fabacher, D., Josephson, K., Pietruszka, F., Linderborn, K., Morley, J., Rubenstein, L. A. (1994). An in-home preventive assessment program for independent older adults: a randomized controlled trial. Journal of the American Geriatric Society, 42, 630-638.

Forster, A., Murff, H., Peterson, J., Gandhi, T., Bates, D. (2003). The incidence and severity of adverse events affecting patients after discharge from hospital. Annals of Internal Medicine, 138(3), 161-7.

García-Montalvo, J. (2011). Voting after the bombings: A natural experiment on the effect of terrorist attacks on democratic elections. Review of Economics and Statistics, 93(4), 11461154.

Geil, P., Million, A., Rotte, R., Zimmermann, K. F. (1997). Economic incentives and hospitalization in Germany. Journal of Applied Econometrics 12, 295-311.

Gené-Badia, J., Gallo, P., Hernández-Quevedo, C., García-Armesto, S. (2012). Spanish health care cuts: penny wise and pound foolish? Health Policy 106(1), 23-28.

Guthrie, E., Dickens, C., Blakemore, A., Watson, J., et al. (2016). Depression predicts future emergency hospital admission in primary care patients with chronic physical illness. Journal of Psychosomatic Research, 82, 54-61.

Gurmu, S., (1998). Generalized hurdle count data regression models. Economics Letters 58(3), 263-268.

IMSERSO (2001). Las personas mayores en España. Informe 2000. Instituto de Mayores y Servicios Sociales

IMSERSO (2003). Las personas mayores en España. Informe 2002. Instituto de Mayores y Servicios Sociales.

IMSERSO (2004), White Book of Dependency: Attention to Dependent People in Spain, Spanish Ministry of Labour and Social Issues.

IMSERSO (2011). Care Coordination White Paper. Ministerio de Sanidad, Política Social e Igualdad. Available at:

https://www.msssi.gob.es/fr/novedades/docs/Libro_Blanco_CCS_15_12_11.pdf

Hendriksen, C., Lund, E., Stromgard, E. (1984). Consequences of assessment and intervention among elderly people: a three year randomized controlled trial. British Medical Journal 289, 1522-1524.

Hofmarcher, M., Oxley, H., Rusticelli, E. (2007). Improved health system performance through better care coordination. Health Working Paper No. 30. Paris: Organisation for Economic Cooperation and Development.

Holmås, T. E., Kjerstad, E., Lurås, H., Straume, O. R. (2008). Does monetary punishment crowd out pro-social motivation? The case of hospital bed-blocking. Núcleo de Investigação em Políticas Económicas. NIPE WP 17/2008.

Holmås, T., Islam, M., Kjerstad, E. (2013). Between two beds: inappropriately delayed discharges from hospitals. International Journal of Health Care Finance Economics 13, 201217. 
Jiménez-Martín. S., Oliva, J., Vilaplana-Prieto, C., Herrera, E., Muñoz-Mayorga, I., Martín Galán, V. (2011). Sanidad y dependencia: matrimonio o divorcio. Círculo de Sanidad. Madrid.

Kalton, G. (1986). Handling wave nonresponse in panel surveys. Journal of Official Statistics, 2, 303-314.

Katz, S. (1983). Assessing self-maintenance: activities of daily living, mobility and instrumental activities of daily living. Journal of the American Geriatric Society, 31(12), 721-726.

Kemper, P., Weaver, F., Short, P., Shea, D., Kang, H. (2008). Meeting the need for personal care among the elderly: does Medicaid home care spending matter? Health Care Services Research 43, 344-362.

Konetzka, R., Karon, S., Potter, D. (2012). Users of Medicaid home and community-based services are especially vulnerable to costly avoidable hospitalizations. Health Affairs 31, 1167-1175.

Legido-Quigley, H., Otero, L., la Parra, D., Álvarez-Dardet, C., Martín-Moreno, J., McKee, M. (2013). Will austerity cuts dismantle the Spanish healthcare system? British Medical Journal 346, pf2363.

Lepkowski, J. M. (1989). Treatment of wave nonresponse in panel surveys. In D. Kasprzyk et al. (eds.) Panel Surveys, New York: Wiley, pp. 348-374.

Malter, F., Börsch-Supan, A. (2013). SHARE Wave 4. Innovations and methodology. Munich Center for the Economics of Aging (MEA)

Majo, M.C., van Soest, A. (2011). The fixed-effects zero-inflated Poisson model with an application to health care utilization. WP Tilburg University No. 2011-083

Molloy, G., McGee, H., O’Neil, D., Conroy, R. (2010). Loneliness and emergency and planned hospitalizations in a community simple of older adults. Journal of the American Geriatric Society, 58(8), 1538-41.

Moreno-Colom, S., Recio Cáceres, C., Torns Martín, T., Borràs Català (2016). Long-term care in Spain: Difficulties in professionalizing services. Journal of Women \& Aging, 1-16. http://dx.doi.org/10.1080/08952841.2015.1125699

Mullahy, J., (1986). Specification and testing of some modified count data models. Journal of Econometrics, 33(3), 341-365.

Mur-Veeman, I., Govers, M. (2011). Buffer management to solve bed-blocking in the Netherlands 2000-2010. Cooperation from an integrated care chain perspective as a key success factor for managing patient flows. International Journal of Integrated Care, 11, 1-10.

Naylor, M. D., Hirschman, K. B., Bowles, K. H., Konick-McMahan, J., Stephens, C. (2007). Care coordination for cognitively impaired older adults and their caregivers. Home Health Care Service Quarterly 26(4), 57-58.

Nielsen, T. H. (2016). The relationship between self-rated health and hospital records. Health Economics, 25(4), 497-512.

Pathy, M., Bayer, A., Harding, K., Dibble, A. (1992). Randomized trial of case finding and surveillance of elderly people at home. Lancet, 340, 890-893. 
Phillips, P. (1983). Exact small sample theory in simultaneous equations model. In Z. Griliches and M. D. Intriligator (eds.), Handbook of Econometrics, vol 1, pp. 449-516. Amsterdam: North Holland.

Picone, G., Wilson, R., Chou, S. (2003). Analysis of hospital length of stay and discharge destination using hazard functions with unmeasured heterogeneity. Health Economics, 12, 1021-1034.

Rapp, T., Chauvin, P., Sirven, N. (2015). Are public subsidies effective to reduce emergency care? Evidence from the PLASA Study. Social Science \& Medicine, 138, 31-37.

Rice, J., Kasper, J., Pezzin, L. (2009). A comparative analysis of Medicaid long-term care policies and their effects on elderly dual enrollees. Health Economics 18, 275-290.

Rubin, D. B. (1987). Multiple imputation for nonresponse in surveys. New York: Wiley.

Sands, L., Wang, Y., McCabe, G., Jennings, K., Eng, C., Covinsky, K. (2006). Rates of acute care admissions for frail older people living with met versus unmet activity of daily living needs. Journal of the American Geriatric Society 54, 339-344.

Scheurer, D., Choudhry, N., Swanton, K. A., Matlin, O., Shrank, W. (2012). Association between different types of social support and medication adherence. American Journal of Managed Care 18(2), e461-e467.

Schwartz, J., Giles, D. (2016). Bias-reduced maximum likelihood estimation of the zero-inflated Poisson distribution. Communications in Statistics: Theory and Methods, 45(2), 465-478.

Seymour, D. G., Pringle, R. (1982). Elderly patients in a general surgical unit: do they block beds? British Medical Journal 284, 1921-1923.

Singh, D., Ham, C. (2005). Transforming chronic care: Evidence about improving care for people with long-term conditions. Birmingham: University of Birmingham, Health Services Management Centre.

Stuck, A., Aronow, H., Steiner, A., Alessi, C., Büla, C., Gold., M., Yuhas, K., Nisenbaum, R., Rubenstein, L., Beck, J. (1995). A trial of annual in-home comprehensive geriatric assessments for elderly people in the community. New England Journal of Medicine, 333, 1184-1189.

Terza, J., Basu, A., Rathouz, P. (2008). Two-stage residual inclusion estimation: addressing endogeneity in health econometric modelling. Journal of Health Economics 27, 531-543.

Tomita, N., Yoshimura, K., Ikegami, N. (2010). Impact of home and community-based services on hospitalisation and institutionalisation among individuals eligible for long-term care insurance in Japan. BMC Health Services Research 10, 345-357.

Van Houtven C. H., Norton, E. (2004). Informal care and health care use of older adults. Journal of Health Economics, 23(6), 1159-1180.

Van Rossum, E., Frederiks, C., Philipsen, H., Portengen, K., Wiskerke, J., Knipschild, P. (1993). Effects of preventive home visits to elderly people. British Medical Journal, 307, 27-32.

Vargas, I., Vázquez, M. L. (2007). Barriers and facilitators to health care coordination in two integrated health care organizations in Catalonia (Spain). Gaceta Sanitaria, 21(2), 114-123.

Xu, H., Weiner, M., Paul, S., Thomas, H., Craig, B., Rosenman, M., Doebbeling, C., Sands, L. (2010). Volume of home-and-community-based Medicaid waiver services and risk of hospital admissions. Journal of the American Geriatric Society 58, 109-115. 
Weaver, F., Weaver, B. (2014). Does availability of informal care within the household impact hospitalization? Health Economics, Policy and Law, 9, 71-93.

Winkelmann, R. (2008). Econometric Analysis of Count Data. $5^{\text {th }}$ edition, Berlin: Springer.

Wooldridge, J. M. (2002). Econometric analysis of cross section and panel data. MIT Press.

Wooldridge, J. M. (2010). Econometrics of cross section and panel data. MIT Press. 


\section{Tables and Figures}

Figure 1. Implementation of the SAAD

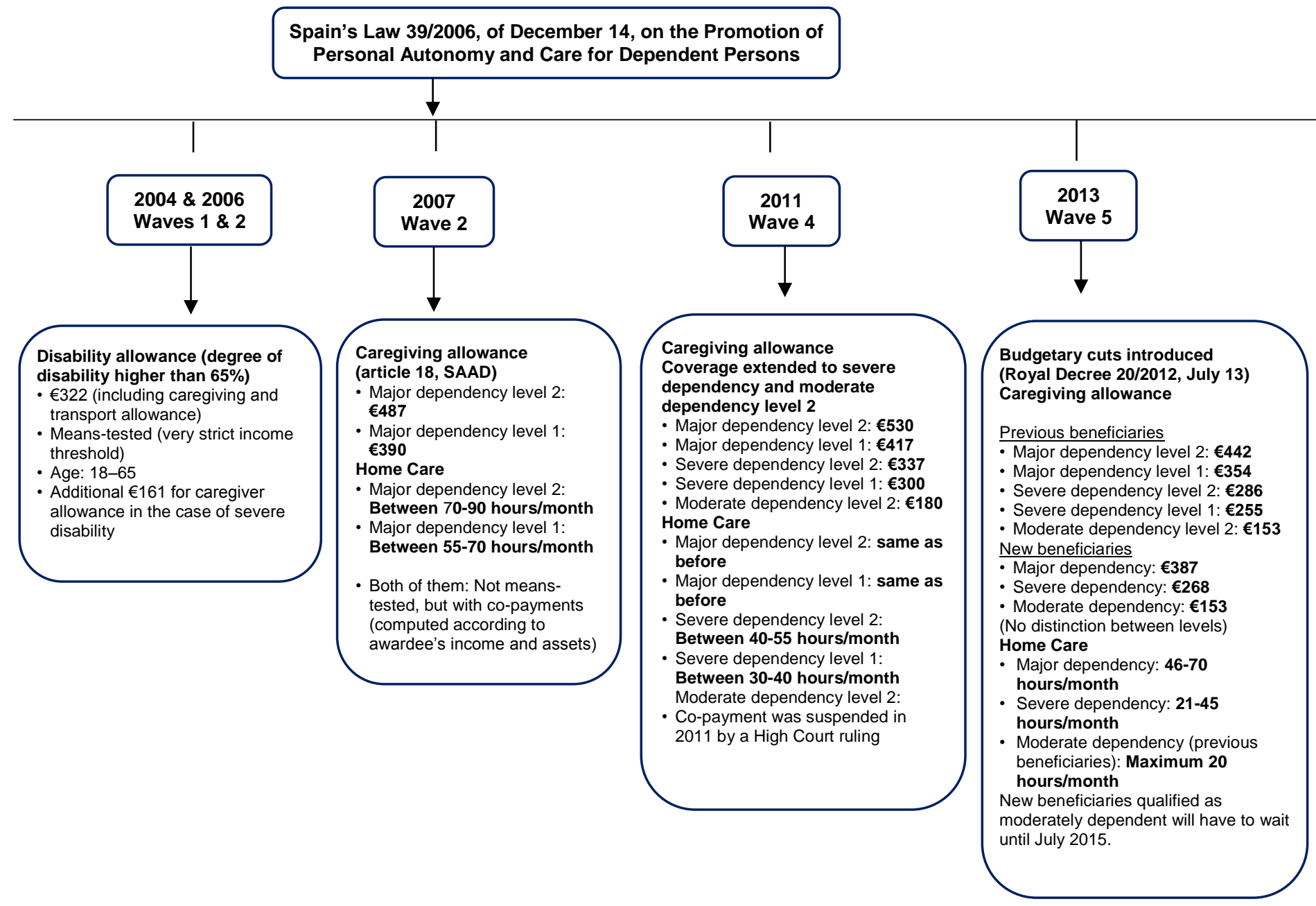

Note: For a better understanding of the amounts of caregiver allowance and disability allowance, they can be compared with Spain's minimum wage of $€ 460.50$ per month (2004), $€ 540.90$ per month (2006), $€ 570.60$ per month (2007), $€ 641.40$ per month (2011) and $€ 645.30$ per month (2013).

Figure 2. Percentage of hospital admissions (extensive margin) by type of subsidy 20042013.

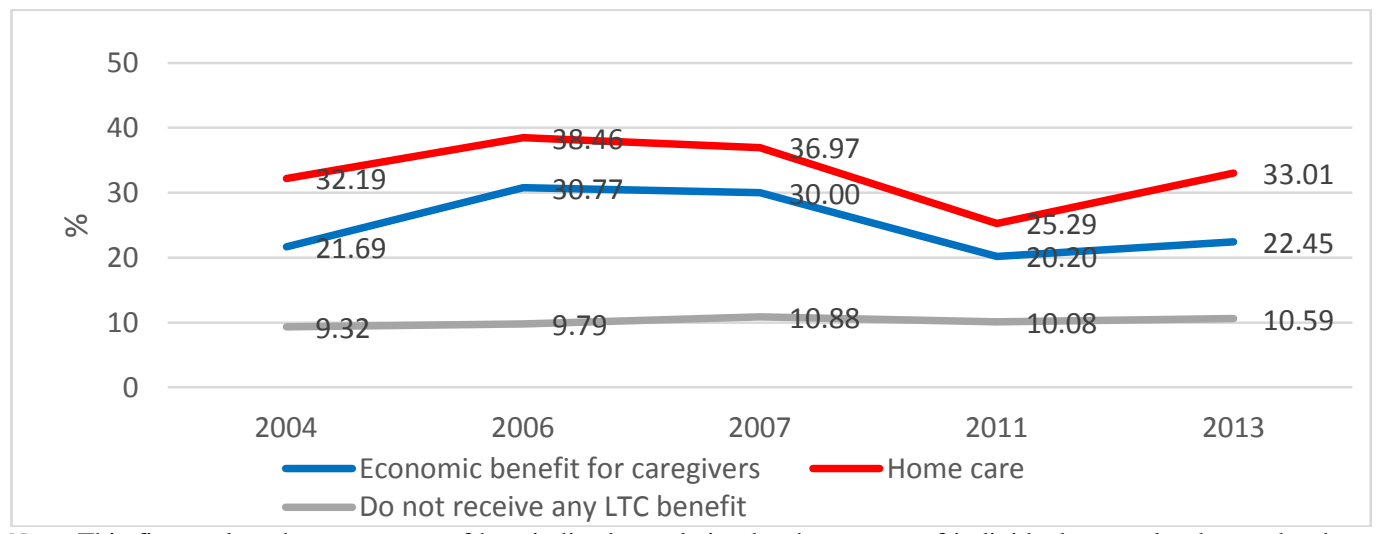

Note: This figure plots the percentage of hospitalized population by three types of individuals, namely, those who do not benefit from the reform, those who receive economic benefits (caregiving allowance), and those who receive a subsidized home care service. 
Figure 3. Density function of hospital Length of Stay by exposure to the 2007 reform and 2012 austerity cuts

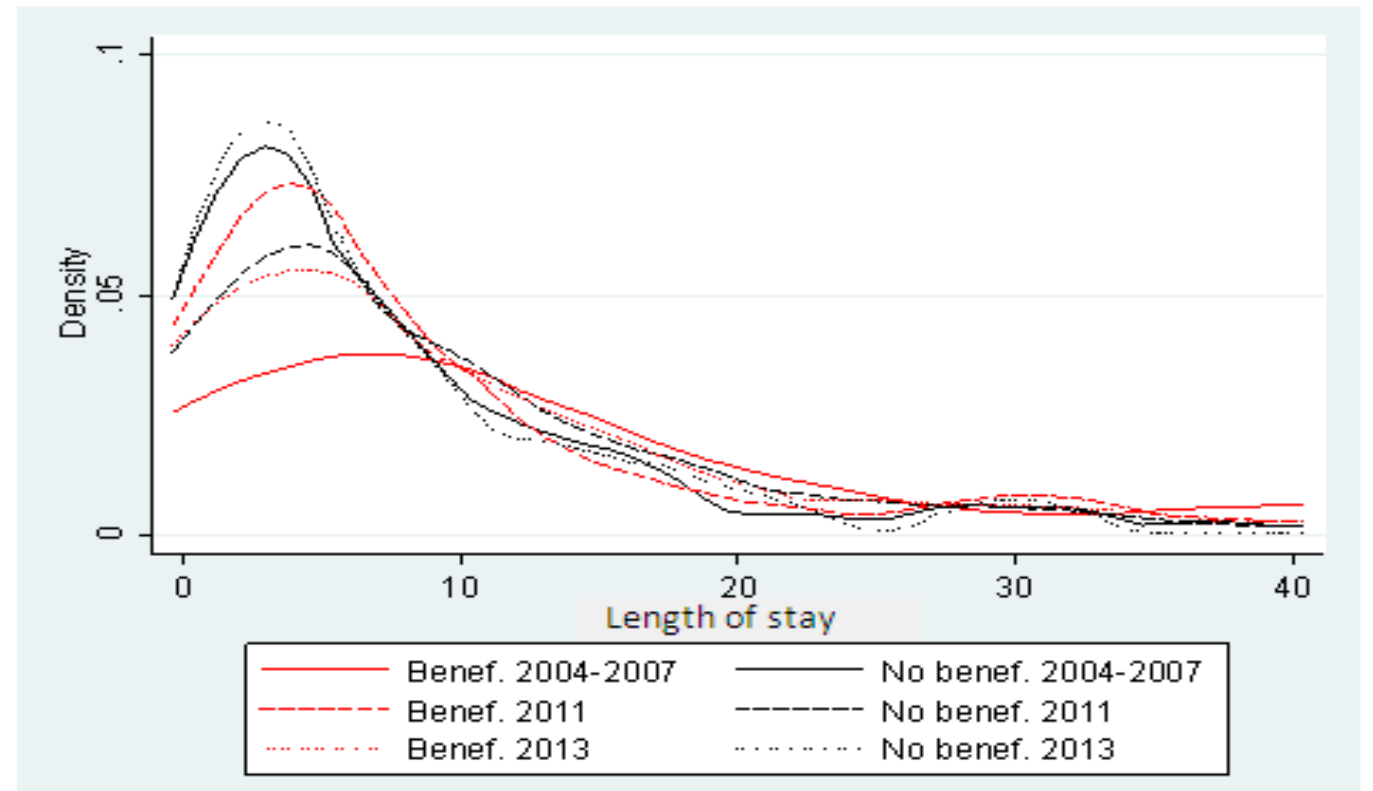

Benef: Beneficiaries. No benef: no beneficiaries

Note: Density function for the number of days hospitalized over last 12 months, distinguishing between beneficiaries of LTC benefits and non-beneficiaries (not receiving either home care benefits or caregiving allowances). Straight lines refer to pre-reform hospitalization for both those affected (red) and those not affected (black) by the reform. Bold dotted lines refer to the post-2007 reform, and light dotted lines refer to those affected by the 2012 reform.

Figure 4. Density function of number of hospital admissions (intensive margin) by exposure to the 2007 reform and 2012 austerity cuts

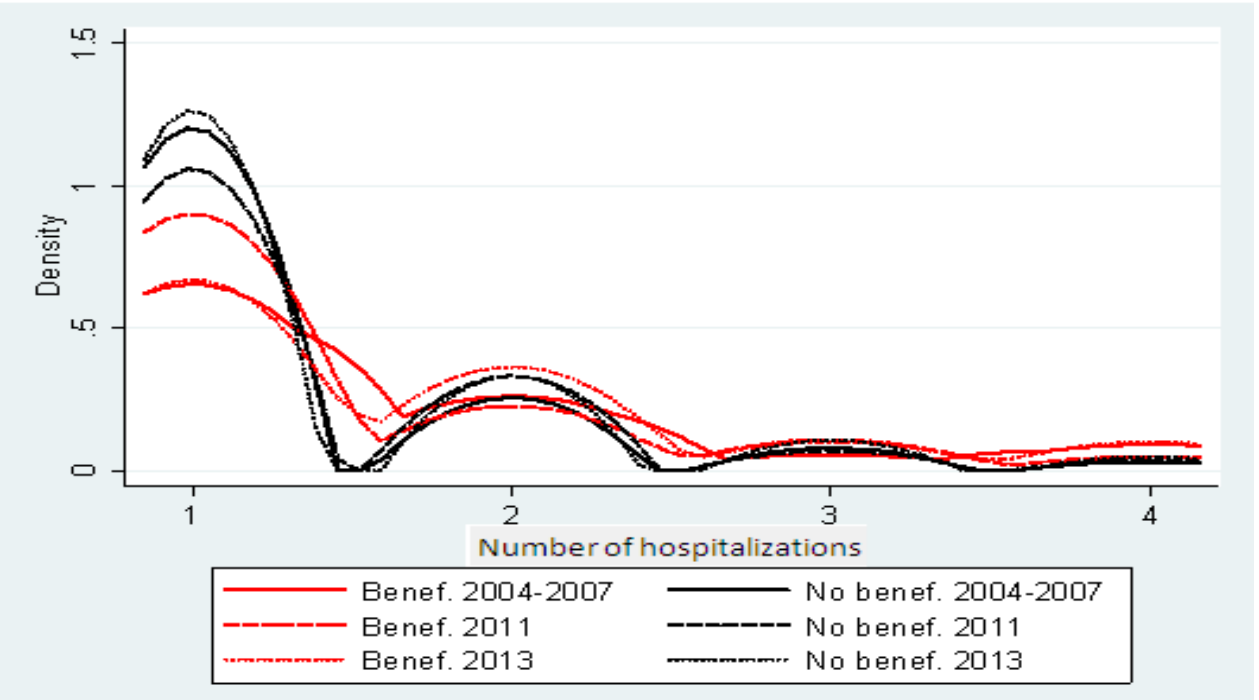

Benef: Beneficiaries. No benef: no beneficiaries

Note: Density function for the number of hospital stays distinguishing between beneficiaries of LTC benefits and non-beneficiaries (not receiving either home care benefits or caregiving allowances). Straight lines refer to pre-reform hospitalization for both those affected (red) and those not affected (black) by the reform. Bold dotted lines refer to the post-2007 reform, and light dotted lines refer to those affected by the 2012 reform. 
Table 1. Coordination between healthcare and LTC services

\begin{tabular}{|c|c|c|}
\hline Region of Spain & Name of the Program or Agency & Period \\
\hline Community of León & Plan de Atención Sociosanitario & $\begin{array}{l}\text { Decree } 59 / 2003 \text {, of January } 23 \\
\text { Coord = } 1 \text { for all waves }\end{array}$ \\
\hline Community of La Mancha & Consejería de Salud y Bienestar Social & $\begin{array}{l}\text { Decree } 139 / 2008 \text {, of September } 9 \\
\text { Coord }=1 \text { for Waves } 4 \text { and } 5\end{array}$ \\
\hline Catalonia & $\begin{array}{l}\text { Plan Director Sociosanitario. Programa Vida } \\
\text { als Anys. } \\
\text { Plan de Atención Sociosanitario } 2000 \\
\text { Plan Director Sociosanitario } 2006\end{array}$ & $\begin{array}{l}\text { Decree } 242 / 1999, \text { of August } 31 \\
\text { Coord = } 1 \text { for all waves }\end{array}$ \\
\hline Community of Valencia & $\begin{array}{l}\text { Programa Especial de la Atención Sanitaria a } \\
\text { pacientes ancianos, a pacientes con } \\
\text { enfermedades de larga evolución y a pacientes } \\
\text { en situación terminal (PALET), } 1995 \text {. }\end{array}$ & Coord $=1$ for all waves \\
\hline Extremadura & Consejería de Sanidad y Dependencia & $\begin{array}{l}\text { Law } 1 / 2008 \text {, of May } 22 \\
\text { Coord }=1 \text { for Waves } 4 \text { and } 5\end{array}$ \\
\hline Navarre & Plan Foral de Atención Sociosanitaria. & $\begin{array}{l}\text { Agreement of the Government of } \\
\text { Navarre of June } 27,2000 \\
\text { Coord }=1 \text { for all waves }\end{array}$ \\
\hline Basque Country & Consejo Vasco de Atención Sociosanitaria & Coord $=1$ for Wave 5 \\
\hline
\end{tabular}

Coord is a binary variable that takes the value 1 if there is a coordination program between healthcare and LTC services in the region, and 0 otherwise. Source: Jiménez-Martín et al. (2011).

Table 2. First-stage regressions

\begin{tabular}{lcccc}
\hline & $C A$ & $C A^{*} \mathrm{POST}$ & $H B$ & $H B^{* \mathrm{POST}}$ \\
\hline Socialist support (\%) & $-0.045^{* * *}$ & $-0.057^{* * *}$ & $0.088^{* *}$ & $0.097^{* * *}$ \\
& $(0.01)$ & $(0.01)$ & $(0.03)$ & $(0.01)$ \\
Socialist support (\%)*POST & $-0.028^{*}$ & $-0.047^{* * *}$ & $0.128^{* *}$ & $0.084^{* *}$ \\
& $(0.01)$ & $(0.01)$ & $(0.05)$ & $(0.02)$ \\
Home Care (2000) & $-0.016^{* *}$ & $-0.006^{*}$ & $0.025^{*}$ & $0.031^{* *}$ \\
& $(0.00)$ & $(0.00)$ & $(0.01)$ & $(0.01)$ \\
Home Care (2002) & $-0.035^{* *}$ & $-0.044^{* *}$ & $0.051^{*}$ & $0.072^{* * *}$ \\
Fraction of women at home & $(0.01)$ & $(0.02)$ & $(0.03)$ & $(0.02)$ \\
& $0.044^{* *}$ & $0.046^{* * *}$ & $-0.023^{*}$ & $-0.018^{*}$ \\
Rural area & $(0.01)$ & $(0.01)$ & $(0.01)$ & $(0.01)$ \\
& $0.022^{* *}$ & $0.021^{* *}$ & $-0.016^{*}$ & $-0.014^{*}$ \\
\hline F-test instrumental variables & $(0.00)$ & $(0.00)$ & $(0.00)$ & $(0.00)$ \\
F(6,14722) & 234.56 & 154.07 & 160.41 & 150.46 \\
\hline $\mathrm{N}$ & $(0.000)$ & $(0.000)$ & $(0.000)$ & $(0.000)$ \\
\hline
\end{tabular}

CA: caregiving allowance. HB: home care benefits. POST: binary variable that takes the value 1 after the implementation of SAAD (i.e., since 2007, and 0 otherwise. Home Care (2000) and Home Care (2002) denote the coverage index of home care benefits at regional level. The coverage index is defined as the ratio between the number of beneficiaries aged 65 and over divided by the total population aged 65 and over. Estimated coefficients for age, gender, marital status, level of education, self-reported health status, Katz Index, real income, real wealth, year and regional dummies are not shown. Standard deviations between parentheses $* * *$ means significance at $1 \%$ level, $* *$ at $5 \%$ level, * at $10 \%$ level. 
Table 3. Hurdle Poisson for number $\left(H N_{i}\right)$ and $\operatorname{LoS}$ of hospital admissions $\left(H L S_{i}\right)$.

\begin{tabular}{|c|c|c|c|c|c|c|}
\hline & \multicolumn{3}{|c|}{$C A_{i}$} & \multicolumn{3}{|c|}{$H B_{i}$} \\
\hline & $\begin{array}{c}H_{i} \\
\text { Logit } \\
\end{array}$ & $\begin{array}{c}H N_{i} \\
\text { Trunc Poisson }\end{array}$ & $\begin{array}{c}H L S_{i} \\
\text { Trunc Poisson }\end{array}$ & $\begin{array}{c}H_{i} \\
\text { Logit } \\
\end{array}$ & $\begin{array}{c}H N_{i} \\
\text { Trunc Poisson }\end{array}$ & $\begin{array}{c}H L S_{i} \\
\text { Trunc Poisson }\end{array}$ \\
\hline \multicolumn{7}{|l|}{ A. Baseline } \\
\hline $\begin{array}{l}\text { SAAD } \\
\text { SAAD*POST }\end{array}$ & $\begin{array}{l}0.078^{* * * *} \\
(0.02) \\
-0.095^{* * *} \\
(0.02)\end{array}$ & $\begin{array}{l}1.134 * * \\
(0.04) \\
0.801 * * \\
(0.10)\end{array}$ & $\begin{array}{l}0.862 * * * \\
(0.05) \\
0.791 * * * \\
(0.06)\end{array}$ & $\begin{array}{l}0.052 * * * \\
(0.01) \\
0.014 \\
(0.02)\end{array}$ & $\begin{array}{l}1.019 \\
(0.09) \\
0.895^{* *} \\
(0.04)\end{array}$ & $\begin{array}{l}1.267 * * * \\
(0.02) \\
0.696 * * * \\
(0.04)\end{array}$ \\
\hline Resid. (SAAD) & $\begin{array}{l}-1.009 \\
(1.93)\end{array}$ & $\begin{array}{l}24.160 * * * \\
(4.34)\end{array}$ & $\begin{array}{l}-17.517 * * * \\
(5.53)\end{array}$ & $\begin{array}{l}0.712 \\
(0.71)\end{array}$ & $\begin{array}{l}-27.375 * * * \\
(7.64)\end{array}$ & $\begin{array}{l}-6.014 * * * \\
(2.03)\end{array}$ \\
\hline Resid. (SAAD* POST) & $\begin{array}{l}-0.045 \\
(0.79)\end{array}$ & $\begin{array}{l}14.005^{* * *} \\
(3.61)\end{array}$ & $\begin{array}{l}14.251^{* * * *} \\
(2.26)\end{array}$ & $\begin{array}{l}1.180 \\
(1.50)\end{array}$ & $\begin{array}{l}22.485^{* * * *} \\
(5.77)\end{array}$ & $\begin{array}{l}4.988 \\
(4.28)\end{array}$ \\
\hline $\begin{array}{l}\text { F-test residuals } \\
\text { (p-value) }\end{array}$ & $\begin{array}{l}0.41 \\
(0.524)\end{array}$ & $\begin{array}{l}63.20 \\
(0.000)\end{array}$ & $\begin{array}{l}56.18 \\
(0.000)\end{array}$ & $\begin{array}{l}0.02 \\
(0.890)\end{array}$ & $\begin{array}{l}61.28 \\
(0.000)\end{array}$ & $\begin{array}{l}48.23 \\
(0.000)\end{array}$ \\
\hline $\begin{array}{l}\text { Hausman test } \\
\left(\chi_{45}^{2} ; \mathrm{p} \text {-value }\right)\end{array}$ & $\begin{array}{l}19.374 \\
(0.999)\end{array}$ & $\begin{array}{l}295.630 \\
(0.000)\end{array}$ & $\begin{array}{l}217.196 \\
(0.000)\end{array}$ & $\begin{array}{l}2.791 \\
1.000\end{array}$ & $\begin{array}{l}278.968 \\
(0.000)\end{array}$ & $\begin{array}{l}591.267 \\
(0.000)\end{array}$ \\
\hline \multicolumn{7}{|l|}{ B. Coordination Plans } \\
\hline SAAD & $\begin{array}{l}0.084 * * * \\
(0.02)\end{array}$ & $\begin{array}{l}1.779 * * \\
(0.25)\end{array}$ & $\begin{array}{l}0.834 * * * \\
(0.06)\end{array}$ & $\begin{array}{l}0.053 * * * \\
(0.01)\end{array}$ & $\begin{array}{l}1.032 \\
(0.10)\end{array}$ & $\begin{array}{l}1.236^{* * * *} \\
(0.02)\end{array}$ \\
\hline SAAD*POST & $\begin{array}{l}-0.077^{* * * *} \\
(0.02)\end{array}$ & $\begin{array}{l}0.862 * * * \\
(0.27)\end{array}$ & $\begin{array}{l}0.818^{* * * *} \\
(0.07)\end{array}$ & $\begin{array}{l}0.016 \\
(0.02)\end{array}$ & $\begin{array}{l}0.892 * * \\
(0.05)\end{array}$ & $\begin{array}{l}0.729 * * * \\
(0.04)\end{array}$ \\
\hline Coordination & $\begin{array}{l}0.038 \\
(0.03)\end{array}$ & $\begin{array}{l}0.958 \\
(0.36)\end{array}$ & $\begin{array}{l}1.027 \\
(0.08)\end{array}$ & $\begin{array}{l}0.038 \\
(0.03)\end{array}$ & $\begin{array}{l}1.021 \\
(0.35)\end{array}$ & $\begin{array}{l}0.924 \\
(0.08)\end{array}$ \\
\hline Coordination* POST & $\begin{array}{l}-0.095^{* * * *} \\
(0.03)\end{array}$ & $\begin{array}{l}1.154 \\
(0.33)\end{array}$ & $\begin{array}{l}1.102 \\
(0.08)\end{array}$ & $\begin{array}{l}-0.089^{* * *} \\
(0.03)\end{array}$ & $\begin{array}{l}1.009 \\
(0.32)\end{array}$ & $\begin{array}{l}0.129 \\
(0.08)\end{array}$ \\
\hline SAAD *Coord & $\begin{array}{l}-0.031 \\
(0.04)\end{array}$ & $\begin{array}{l}1.333 * * * \\
(0.36)\end{array}$ & $\begin{array}{l}1.030 \\
(0.12)\end{array}$ & $\begin{array}{l}-0.019 \\
(0.03)\end{array}$ & $\begin{array}{l}1.484 \\
(0.26)\end{array}$ & $\begin{array}{l}1.426^{* * * *} \\
(0.07)\end{array}$ \\
\hline SAAD* Coord *POST & $\begin{array}{l}-0.116^{*} \\
(0.06)\end{array}$ & $\begin{array}{l}0.862 * * * \\
(0.01)\end{array}$ & $\begin{array}{l}1.120 \\
(0.18)\end{array}$ & $\begin{array}{l}-0.185^{* * *} \\
(0.02)\end{array}$ & $\begin{array}{l}0.793 \text { *** } \\
(0.05)\end{array}$ & $\begin{array}{l}0.667 * * * \\
(0.17)\end{array}$ \\
\hline F-test for residuals & $\begin{array}{l}0.25 \\
(0.615) \\
\end{array}$ & $\begin{array}{l}77.33 \\
(0.000) \\
\end{array}$ & $\begin{array}{l}78.96 \\
(0.000) \\
\end{array}$ & $\begin{array}{l}0.40 \\
(0.526) \\
\end{array}$ & $\begin{array}{l}75.46 \\
(0.000) \\
\end{array}$ & $\begin{array}{l}80.23 \\
(0.000)\end{array}$ \\
\hline \multicolumn{7}{|l|}{ C. Effect of budgetary cuts } \\
\hline SAAD & $\begin{array}{l}0.078^{* * * *} \\
(0.02)\end{array}$ & $\begin{array}{l}0.836 \\
(0.18)\end{array}$ & $\begin{array}{l}0.862^{* * * *} \\
(0.05)\end{array}$ & $\begin{array}{l}0.052^{* * *} \\
(0.01)\end{array}$ & $\begin{array}{l}1.014 \\
(0.09)\end{array}$ & $\begin{array}{l}1.269^{* * *} \\
(0.02)\end{array}$ \\
\hline SAAD*POST (2011\&2013) & $\begin{array}{l}-0.104 * \\
(0.06)\end{array}$ & $\begin{array}{l}0.887 \\
(0.70)\end{array}$ & $\begin{array}{l}0.864 * * * \\
(0.05)\end{array}$ & $\begin{array}{l}-0.028 \\
(0.07)\end{array}$ & $\begin{array}{l}0.517 \\
(0.97)\end{array}$ & $\begin{array}{l}0.871 \text { *** } \\
(0.21)\end{array}$ \\
\hline SAAD*POST (2013) & $\begin{array}{l}-0.288 \\
(2.61)\end{array}$ & $\begin{array}{l}1.161 * * \\
(0.05)\end{array}$ & $\begin{array}{l}1.287 * * \\
(0.60)\end{array}$ & $\begin{array}{l}0.656 \\
(1.37)\end{array}$ & $\begin{array}{l}1.399 \text { *** } \\
(0.07)\end{array}$ & $\begin{array}{l}1.484 * * \\
(0.29)\end{array}$ \\
\hline F-test for residuals & $\begin{array}{l}0.59 \\
(0.443) \\
\end{array}$ & $\begin{array}{l}87.15 \\
(0.000)\end{array}$ & $\begin{array}{l}80.91 \\
(0.000)\end{array}$ & $\begin{array}{l}0.06 \\
(0.802)\end{array}$ & $\begin{array}{l}84.87 \\
(0.000)\end{array}$ & $\begin{array}{l}87.23 \\
(0.000)\end{array}$ \\
\hline $\mathrm{N}$ & 14,766 & 1,705 & 1,705 & 14,766 & 1,705 & 1,705 \\
\hline
\end{tabular}

$S A A D_{i}$ : binary variable representing the treatment group that takes the value 1 for individuals receiving LTC benefits (either care giving allowances $\left(C A_{i}\right)$ or home care benefits $\left.\left(H B_{i}\right)\right)$. H: having been hospitalized in the last 12 months. HN: number of hospitalizations in the last 12 months. HLS: length of stay at hospital during all hospitalizations in the last 12 months. POST: binary variable that takes the value 1 after the reform in the Spanish LTC system.

Notes: Logit for the first hurdle; zero truncated Poisson for the second hurdle (two alternative dependent variables). Marginal effects are shown for the first hurdle; incidence rate ratios are shown for the second hurdle. For residuals, we report the estimated coefficients. Bootstrap with 100 repetitions. The first hurdle $\left(H_{i}\right)$ coincides for both hurdle Poisson models.

Estimated coefficients for age, gender, marital status, level of education, self-reported health status, Katz Index, real income, real wealth, per capita public healthcare expenditure, number of public hospital beds per 1,000 inhabitants, satisfaction with public healthcare system, infection rate at hospital, year and regional dummies are not shown. Standard deviations between parentheses. $* * *$ means significance at $1 \%$ level, ** at $5 \%$ level, * at $10 \%$ level.

Baseline: F-test of residuals is distributed according to $\mathrm{F}(2,14726)$ for the logit model, and $\mathrm{F}(2,1665)$ for the truncated Poisson.

Coordination case: F-test of residuals is distributed according to F(4,14724) for the logit model, and F(4,1663) for the truncated Poisson.

Effect of budgetary cuts: F-test of residuals is distributed according to $F(3,14725)$ for the logit model, and $F(3,1664)$ for the truncated Poisson. 
Table 4. Estimation of SAAD's impact on hospital costs (Figures in euros)

\begin{tabular}{|c|c|c|c|c|c|}
\hline & \multicolumn{3}{|c|}{ Reduction/increase in hospital costs due to } & \multirow{2}{*}{$\begin{array}{l}\text { Hospital costs* } \\
2007\end{array}$} & \multirow{2}{*}{$\begin{array}{l}(1)+(2) \mathrm{w} / \mathrm{r} \text { to } \\
\text { hospital costs } \\
\%\end{array}$} \\
\hline & $\begin{array}{l}C A_{i} \\
(1)\end{array}$ & $\begin{array}{c}H B_{i} \\
(2)\end{array}$ & $\begin{array}{c}\text { Total } \\
(1)+(2)\end{array}$ & & \\
\hline $\begin{array}{l}\text { Number of hospital } \\
\text { admissions } \\
\text { Base Case }\end{array}$ & & & & & \\
\hline Coordination & $\begin{array}{c}-609,147,824 \\
(-583,563,615,-639,605,215)\end{array}$ & $\begin{array}{c}-120,235,688 \\
(-114,464,375,-126,007,001)\end{array}$ & $\begin{array}{c}-729,383,512 \\
(-698,027,990,-765,612,216)\end{array}$ & $14,727,559,994$ & -4.95 \\
\hline & $\begin{array}{c}-160,527,318 \\
(-152,822,007,-167,269,465)\end{array}$ & $\begin{array}{c}-34,122,441 \\
(-32,894,033,-35,350,849)\end{array}$ & $\begin{array}{c}-194,649,758 \\
(-185,716,040,-202,620,314)\end{array}$ & $7,063,627,888$ & -2.75 \\
\hline $\begin{array}{l}\text { SAAD's impact } \\
2013\end{array}$ & $\begin{array}{c}239,468,171 \\
(239,468,171,250,962,643)\end{array}$ & $\begin{array}{c}290,442,486 \\
(278,824,787,302,060,185)\end{array}$ & $\begin{array}{c}529,910,657 \\
(518,292,958,553,022,829)\end{array}$ & $14,727,559,994$ & 3.60 \\
\hline $\begin{array}{l}\text { Hospital length of } \\
\text { stay } \\
\text { Base Case }\end{array}$ & & & & & \\
\hline Coordination & $\begin{array}{c}-600,824,472 \\
(-553,960,163,-638,075,589) \\
\text { No signif, } \\
-\end{array}$ & $\begin{array}{c}-314,387,318 \\
(-296,152,854,-33,2621,782) \\
-112,975,580 \\
(-106,761,923,-119,189,237)\end{array}$ & $\begin{array}{c}-915,211,790 \\
(-850,113,017,-970,697,372) \\
-173,439,479 \\
(-106,761,923,-119,189,237)\end{array}$ & $\begin{array}{r}14,727,559,994 \\
7,063,627,888\end{array}$ & $\begin{array}{l}-6.22 \\
-2.46\end{array}$ \\
\hline $\begin{array}{l}\text { SAAD's impact } \\
2013\end{array}$ & $\begin{array}{c}233,564,656 \\
(233,564,656,248,746,359)\end{array}$ & $\begin{array}{c}71,077,192 \\
(67,239,024,74,915,360)\end{array}$ & $\begin{array}{c}304,641,847 \\
(300,803,680,323,661,719)\end{array}$ & $14,727,559,994$ & 2.07 \\
\hline $\begin{array}{l}\text { Total effect } \\
\text { Base Case }\end{array}$ & & & & & \\
\hline Coordination & $\begin{array}{c}-1,209,972,296 \\
(-1,141,003,875,-1,264,421,049)\end{array}$ & $\begin{array}{c}-434,623,006 \\
(-408,980,249,-460,265,763)\end{array}$ & $\begin{array}{c}-1,644,595,302 \\
(-1549,984,124,-172,4686,813)\end{array}$ & $14,727,559,994$ & -11.17 \\
\hline & $\begin{array}{c}-160,527,318 \\
(-150,414,097,-169,677,375)\end{array}$ & $\begin{array}{c}-147,098,021 \\
(-138,272,140,-155,923,902)\end{array}$ & $\begin{array}{c}-368,089,237 \\
(-288,686,237,-325,601,277)\end{array}$ & $7,063,627,888$ & -5.21 \\
\hline $\begin{array}{l}\text { SAAD’s impact } \\
2013\end{array}$ & $\begin{array}{c}473,032,827 \\
(443231759,502833895) \\
\end{array}$ & $\begin{array}{c}361,519,678 \\
(344,166,733,378,872,623) \\
\end{array}$ & $\begin{array}{c}834,552,504 \\
(817,199,560,881,706,518) \\
\end{array}$ & $14,727,559,994$ & 5.67 \\
\hline $\begin{array}{l}\text { Consultations with } \\
\text { General } \\
\text { Practitioner }\end{array}$ & $\begin{array}{c}24,114,377 \\
(22691629,25537125)\end{array}$ & $\begin{array}{c}8,094,675 \\
(7687440,8458935) \\
\end{array}$ & $\begin{array}{c}32,209,052 \\
(30598559,33819505) \\
\end{array}$ & $10,509,486,000$ & 0.31 \\
\hline
\end{tabular}

CA: caregiving allowance. HB: home care benefits. Confidence intervals between parentheses

Cost data refer to Spain for the base case. For the other cases, hospital costs are computed as the sum of hospital costs in the affected regions.

Data on hospital costs from the Ministry of Health, Social Affairs and Immigration:

http://pestadistico.inteligenciadegestion.msssi.es/publicoSNS/comun/DefaultPublico.aspx

Data on total costs linked to consultations with GP:

https://www.msssi.gob.es/estadEstudios/estadisticas/sisInfSanSNS/pdf/egspGastoReal.pdf

Cost per consultation with GP from Resolution of June 30, 2006: $74 € /$ visit 


\title{
Appendix to the paper 'Does Long-Term Care Subsidization Reduce Hospital Admissions and Utilization?' by Joan Costa-Font, Sergi Jimenez-Martin and Cristina Vilaplana.
}

\author{
Appendix A. Descriptive and imputation statistics
}

Table. A1 Percentage of population aged 65 and over

\begin{tabular}{|c|c|c|c|c|}
\hline & 2004 & 2007 & 2011 & 2013 \\
\hline Andalusia & 14.76 & 14.63 & 15.21 & 15.65 \\
\hline Aragón & 20.97 & 20.16 & 19.97 & 20.22 \\
\hline Asturias & 22.13 & 21.91 & 22.36 & 23.06 \\
\hline Balearic Isles & 13.87 & 13.69 & 14.25 & 14.67 \\
\hline Canary Islands & 12.06 & 12.44 & 13.80 & 14.45 \\
\hline Cantabria & 18.99 & 18.57 & 18.74 & 19.32 \\
\hline Community of León & 22.80 & 22.52 & 22.82 & 23.29 \\
\hline Community of La Mancha & 19.43 & 18.28 & 17.61 & 17.71 \\
\hline Catalonia & 16.92 & 16.42 & 16.78 & 17.33 \\
\hline Community of Valencia & 16.30 & 16.25 & 17.14 & 17.90 \\
\hline Extremadura & 19.26 & 18.99 & 19.18 & 19.37 \\
\hline Galicia & 21.32 & 21.58 & 22.52 & 23.15 \\
\hline Madrid & 14.48 & 14.40 & 15.01 & 15.75 \\
\hline Murcia & 14.09 & 13.75 & 14.05 & 14.53 \\
\hline Navarre & 17.68 & 17.45 & 17.62 & 18.14 \\
\hline Basque Country & 18.24 & 18.54 & 19.54 & 20.22 \\
\hline La Rioja & 18.96 & 18.36 & 18.46 & 18.94 \\
\hline Ceuta & 10.93 & 10.93 & 10.57 & 10.32 \\
\hline Spain & 16.90 & 16.66 & 17.15 & 17.69 \\
\hline
\end{tabular}

Table A2. Ratios of dependency assessment and award of benefits by year and region

\begin{tabular}{|c|c|c|c|c|c|c|}
\hline & \multicolumn{3}{|c|}{$\frac{\text { Assessments }}{\text { Applications }} * 100$} & \multicolumn{3}{|c|}{$\frac{\text { Awarded benefits }}{\text { Assessments }} * 100$} \\
\hline & 2008 & 2011 & 2013 & 2008 & 2011 & 2013 \\
\hline Andalusia & 70.04 & 66.36 & 88.18 & 77.14 & 89.86 & 65.80 \\
\hline Aragón & 89.09 & 70.13 & 97.13 & 80.38 & 76.62 & 62.10 \\
\hline Asturias & 62.40 & 61.28 & 94.44 & 85.31 & 73.00 & 55.89 \\
\hline Balearic Isles & 32.01 & 70.83 & 97.85 & 81.74 & 61.08 & 64.61 \\
\hline Canary Islands & 36.92 & 69.40 & 75.53 & 78.41 & 38.49 & 81.75 \\
\hline Cantabria & 67.74 & 79.78 & 99.90 & 68.62 & 81.75 & 68.94 \\
\hline Community of León & 96.82 & 74.19 & 95.69 & 80.14 & 98.42 & 63.49 \\
\hline Community of La Mancha & 67.12 & 63.04 & 95.11 & 77.20 & 88.95 & 57.38 \\
\hline Catalonia & 95.56 & 71.84 & 96.98 & 85.54 & 74.18 & 59.91 \\
\hline Community of Valencia & 92.67 & 67.84 & 98.05 & 87.61 & 62.74 & 61.47 \\
\hline Extremadura & 71.12 & 64.52 & 95.63 & 70.47 & 65.94 & 56.81 \\
\hline Galicia & 64.95 & 70.01 & 97.74 & 82.45 & 55.13 & 71.69 \\
\hline Madrid & 96.21 & 69.34 & 98.05 & 92.25 & 95.26 & 58.47 \\
\hline Murcia & 100.00 & 76.89 & 81.03 & 100.00 & 81.11 & 76.20 \\
\hline Navarre & 63.66 & 65.92 & 97.09 & 56.53 & 86.09 & 54.84 \\
\hline Basque Country & 99.99 & 65.75 & 97.25 & 100.00 & 88.37 & 56.79 \\
\hline La Rioja & 66.95 & 68.11 & 99.99 & 82.85 & 100.00 & 52.72 \\
\hline Ceuta & 91.92 & 60.02 & 96.56 & 71.51 & 93.36 & 53.86 \\
\hline Spain & 75.43 & 68.69 & 93.82 & 81.46 & 80.53 & 62.61 \\
\hline
\end{tabular}

Source: Own work using data from the Ministry of Health, Social Services and Equality. First available data correspond to May

2008. Data for 2011 and 2013 correspond to the month of July. 
Table A3. Description of the initial sample and the missing values by region

\begin{tabular}{|c|c|c|c|c|c|c|}
\hline & \multicolumn{2}{|c|}{ Initial sample } & \multicolumn{2}{|c|}{$\begin{array}{c}\text { Missing values for } \\
\text { hospitalization variables }\end{array}$} & \multicolumn{2}{|c|}{ Final sample } \\
\hline & $\mathrm{N}$ & $\%$ & $\mathrm{~N}$ & $\%$ & $\mathrm{~N}$ & $\%$ \\
\hline Andalusia & 3,329 & 22,41 & 12 & 13,33 & 3,238 & 21,93 \\
\hline Aragón & 471 & 3,17 & 0 & 0,00 & 483 & 3,27 \\
\hline Asturias & 344 & 2,32 & 2 & 2,22 & 294 & 1,99 \\
\hline Balearic Isles & 158 & 1,07 & 2 & 2,22 & 142 & 0,96 \\
\hline Canary Islands & 649 & 4,37 & 0 & 0,00 & 597 & 4,04 \\
\hline Cantabria & 156 & 1,05 & 2 & 2,22 & 162 & 1,10 \\
\hline Community of León & 1,054 & 7,10 & 0 & 0,00 & 1,034 & 7,00 \\
\hline Community of La Mancha & 1,003 & 6,75 & 0 & 0,00 & 1,035 & 7,01 \\
\hline Catalonia & 2,059 & 13,86 & 14 & 15,56 & 2,199 & 14,90 \\
\hline Community of Valencia & 1,632 & 10,99 & 10 & 11,11 & 1,561 & 10,57 \\
\hline Extremadura & 272 & 1,83 & 0 & 0,00 & 342 & 2,31 \\
\hline Galicia & 626 & 4,21 & 16 & 17,78 & 534 & 3,61 \\
\hline Madrid & 1,670 & 11,24 & 20 & 22,22 & 1,703 & 11,53 \\
\hline Murcia & 578 & 3,89 & 6 & 6,67 & 612 & 4,15 \\
\hline Navarre & 272 & 1,83 & 0 & 0,00 & 267 & 1,81 \\
\hline Basque Country & 401 & 2,70 & 2 & 2,22 & 376 & 2,55 \\
\hline Rioja & 159 & 1,07 & 4 & 4,44 & 174 & 1,18 \\
\hline Ceuta & 21 & 0,14 & 0 & 0,00 & 13 & 0,09 \\
\hline Total & 14,854 & 100 & 88 & 100,00 & 14,766 & 100 \\
\hline
\end{tabular}

Note: We have obtained the final sample by discarding observations for which the codes "refusal" or "don't know" had been registered for the following variables: "having been hospitalized over the last 12 months", "number of hospitalizations over the last 12 months" and "total number of nights in hospital over the last 12 months".

Table A4. Description of final samples by wave and region

\begin{tabular}{|c|c|c|c|c|c|c|c|c|}
\hline & \multicolumn{2}{|c|}{$\begin{array}{c}\text { Final sample } \\
\text { Wave } 1\end{array}$} & \multicolumn{2}{|c|}{$\begin{array}{c}\text { Final sample } \\
\text { Wave } 2\end{array}$} & \multicolumn{2}{|c|}{$\begin{array}{c}\text { Final sample } \\
\text { Wave } 4\end{array}$} & \multicolumn{2}{|c|}{$\begin{array}{c}\text { Final sample } \\
\text { Wave } 5\end{array}$} \\
\hline & $\mathrm{N}$ & $\%$ & $\mathrm{~N}$ & $\%$ & $\mathrm{~N}$ & $\%$ & $\mathrm{~N}$ & $\%$ \\
\hline Andalusia & 556 & 24.57 & 566 & 24.49 & 760 & 20.72 & 1,355 & 20.76 \\
\hline Aragón & 70 & 3.11 & 68 & 2.96 & 124 & 3.37 & 221 & 3.38 \\
\hline Asturias & 65 & 2.89 & 67 & 2.91 & 58 & 1.57 & 103 & 1.58 \\
\hline Balearic Isles & 36 & 1.6 & 24 & 1.04 & 35 & 0.95 & 47 & 0.72 \\
\hline Canary Islands & 122 & 5.4 & 103 & 4.47 & 142 & 3.87 & 230 & 3.52 \\
\hline Cantabria & 24 & 1.08 & 19 & 0.83 & 43 & 1.18 & 75 & 1.15 \\
\hline Community of León & 138 & 6.09 & 184 & 7.96 & 243 & 6.63 & 468 & 7.18 \\
\hline Community of La Mancha & 135 & 5.96 & 171 & 7.38 & 232 & 6.34 & 497 & 7.61 \\
\hline Catalonia & 255 & 11.27 & 250 & 10.82 & 628 & 17.13 & 1,069 & 16.38 \\
\hline Community of Valencia & 255 & 11.27 & 283 & 12.22 & 371 & 10.11 & 652 & 9.99 \\
\hline Extremadura & 15 & 0.65 & 10 & 0.42 & 121 & 3.31 & 197 & 3.02 \\
\hline Galicia & 124 & 5.48 & 137 & 5.93 & 121 & 3.31 & 150 & 2.3 \\
\hline Madrid & 232 & 10.28 & 245 & 10.61 & 414 & 11.29 & 811 & 12.43 \\
\hline Murcia & 83 & 3.67 & 70 & 3.02 & 165 & 4.49 & 296 & 4.53 \\
\hline Navarre & 43 & 1.9 & 46 & 1.98 & 66 & 1.8 & 112 & 1.72 \\
\hline Basque Country & 79 & 3.5 & 46 & 1.98 & 97 & 2.64 & 155 & 2.37 \\
\hline Rioja & 21 & 0.95 & 17 & 0.73 & 47 & 1.29 & 89 & 1.36 \\
\hline Ceuta & 7 & 0.33 & 6 & 0.25 & 0 & 0 & 0 & 0 \\
\hline Total & 2,253 & 100.00 & 2,361 & 100.00 & 3,627 & 100.00 & 6,525 & 100.00 \\
\hline
\end{tabular}

Note: Final sample corresponding to each wave of SHARE after discarding 88 observations with missing values for hospitalization variables. 
Table A5. Comparison between imputed data for public home care benefit and official data

\begin{tabular}{|c|c|c|c|c|c|c|c|c|}
\hline & \multicolumn{4}{|c|}{$\begin{array}{c}\text { Comparison between imputations for public } \\
\text { home care benefit and official data }\end{array}$} & \multicolumn{4}{|c|}{$\begin{array}{l}\text { Home Care beneficiaries in Wave } 2 \text { that } \\
\text { continue in Wave } 4\end{array}$} \\
\hline & \multicolumn{2}{|c|}{$\begin{array}{l}\text { Official data } \\
\text { Home Care } \\
\text { June } 2011\end{array}$} & \multicolumn{2}{|c|}{$\begin{array}{l}\text { Imputations } \\
\text { Home Care }\end{array}$} & \multicolumn{2}{|c|}{$\begin{array}{c}\text { Distribution of Wave } \\
2 \text { beneficiaries that } \\
\text { continue in Wave } 4\end{array}$} & \multicolumn{2}{|c|}{$\begin{array}{c}\text { Number identified } \\
\text { with the imputation } \\
\text { process }\end{array}$} \\
\hline & $\mathrm{N}$ & $\%$ & $\mathrm{~N}$ & $\%$ & $\mathrm{~N}$ & $\%$ & $\mathrm{~N}$ & $\%$ \\
\hline Andalusia & 47,941 & 43.35 & 41,514 & 40.02 & 11,995 & 54.04 & 11,395 & 54.60 \\
\hline Aragón & 0 & 0.00 & 2,292 & 2.21 & 376 & 1.69 & 341 & 1.63 \\
\hline Asturias & 1,822 & 1.65 & 1,504 & 1.45 & 247 & 1.11 & 220 & 1.05 \\
\hline Balearic Isles & 0 & 0.00 & 695 & 0.67 & 114 & 0.51 & 101 & 0.48 \\
\hline Canary Islands & 0 & 0.00 & 1,504 & 1.45 & 247 & 1.11 & 213 & 1.02 \\
\hline Cantabria & 763 & 0.69 & 571 & 0.55 & 94 & 0.42 & 70 & 0.34 \\
\hline Community of León & 6,955 & 6.29 & 6,203 & 5.98 & 1,017 & 4.58 & 957 & 4.59 \\
\hline Community of La Mancha & 6,228 & 5.63 & 5197 & 5.01 & 852 & 3.84 & 803 & 3.85 \\
\hline Catalonia & 13,428 & 12.14 & 10,508 & 10.13 & 1,723 & 7.76 & 1,658 & 7.94 \\
\hline Community of Valencia & 0 & 0.00 & 1,390 & 1.34 & 228 & 1.03 & 199 & 0.95 \\
\hline Extremadura & 689 & 0.62 & 446 & 0.43 & 73 & 0.33 & 55 & 0.26 \\
\hline Galicia & 5,841 & 5.28 & 5612 & 5.41 & 920 & 4.15 & 845 & 4.05 \\
\hline Madrid & 19,510 & 17.64 & 17,334 & 16.71 & 2,842 & 12.80 & 2,712 & 13.00 \\
\hline Murcia & 0 & 0.00 & 1,162 & 1.12 & 190 & 0.86 & 165 & 0.79 \\
\hline Navarre & 409 & 0.37 & 633 & 0.61 & 104 & 0.47 & 75 & 0.36 \\
\hline Basque Country & 4,589 & 4.15 & 5238 & 5.05 & 859 & 3.87 & 799 & 3.83 \\
\hline Rioja & 2,072 & 1.87 & 1,712 & 1.65 & 281 & 1.26 & 240 & 1.15 \\
\hline Ceuta & 339 & 0.31 & 218 & 0.21 & 36 & 0.16 & 21 & 0.10 \\
\hline Total & 110,586 & 100 & 103,732 & 100 & 22,195 & 100 & 20,869 & 100 \\
\hline Number of observations (SHARE) & & & 180 & & 100 & & 102 & \\
\hline
\end{tabular}

Note: Official data on home care benefits from the Ministry of Health, Social Services and Equality corresponding to June 2011 and own imputations of public home care benefits for Wave 4 .

Table A6. Comparison between National Health Survey and SHARE

\begin{tabular}{|c|c|c|c|c|c|c|}
\hline & \multicolumn{3}{|c|}{ National Health Survey } & \multicolumn{3}{|c|}{ SHARE } \\
\hline & 2003 & 2006 & 2011 & $\begin{array}{c}\text { Wave } 1 \\
2004\end{array}$ & $\begin{array}{c}\text { Wave } 2 \\
2006 / 07\end{array}$ & $\begin{array}{c}\text { Wave } 4 \\
2011 \\
\end{array}$ \\
\hline \multicolumn{7}{|c|}{ Percentage of hospitalizations } \\
\hline Andalusia & 14.43 & 10.64 & 9.70 & 12.85 & 10.43 & 12.37 \\
\hline Aragón & 17.18 & 11.53 & 11.65 & 14.72 & 11.88 & 14.78 \\
\hline Asturias & 17.77 & 11.79 & 11.55 & 15.16 & 11.97 & 15.04 \\
\hline Balearic Isles & 16.61 & 14.78 & 16.92 & 16.10 & 16.26 & 17.20 \\
\hline Canary Islands & 11.91 & 10.00 & 11.24 & 11.23 & 10.89 & 11.87 \\
\hline Cantabria & 12.66 & 14.44 & 10.99 & 13.90 & 13.04 & 12.13 \\
\hline Community of León & 11.17 & 12.10 & 10.81 & 11.93 & 11.75 & 11.27 \\
\hline Community of La Mancha & 13.52 & 15.33 & 11.68 & 14.80 & 13.85 & 12.92 \\
\hline Catalonia & 16.31 & 14.97 & 13.79 & 16.04 & 14.75 & 15.44 \\
\hline Community of Valencia & 15.39 & 12.81 & 11.52 & 14.46 & 12.48 & 13.80 \\
\hline Extremadura & 13.00 & 13.58 & 15.97 & 13.63 & 15.15 & 14.85 \\
\hline Galicia & 12.20 & 12.29 & 9.62 & 12.56 & 11.24 & 11.19 \\
\hline Madrid & 17.40 & 12.91 & 10.90 & 15.54 & 12.21 & 14.51 \\
\hline Murcia & 12.15 & 15.86 & 13.86 & 14.36 & 15.24 & 13.34 \\
\hline Navarre & 12.90 & 11.01 & 7.89 & 12.26 & 9.69 & 10.66 \\
\hline Basque Country & 14.30 & 14.32 & 11.37 & 14.68 & 13.17 & 13.16 \\
\hline Rioja & 8.89 & 11.97 & 12.05 & 10.70 & 12.32 & 10.74 \\
\hline Ceuta & 10.72 & 19.66 & 11.07 & 15.58 & 15.76 & 11.17 \\
\hline \multicolumn{7}{|l|}{ Number of hospitalizations } \\
\hline Andalusia & 1.49 & 1.33 & 1.47 & 1.44 & 1.44 & 1.52 \\
\hline Aragón & 1.31 & 1.40 & 1.39 & 1.39 & 1.43 & 1.39 \\
\hline Asturias & 1.91 & 1.22 & 1.15 & 1.60 & 1.22 & 1.57 \\
\hline Balearic Isles & 1.26 & 1.33 & 1.69 & 1.33 & 1.55 & 1.51 \\
\hline Canary Islands & 1.24 & 1.45 & 1.33 & 1.38 & 1.43 & 1.32 \\
\hline Cantabria & 1.24 & 1.35 & 1.14 & 1.33 & 1.27 & 1.22 \\
\hline Community of León & 1.27 & 1.28 & 1.51 & 1.31 & 1.43 & 1.43 \\
\hline Community of La Mancha & 1.36 & 1.29 & 1.34 & 1.36 & 1.35 & 1.38 \\
\hline Catalonia & 1.55 & 1.40 & 1.36 & 1.52 & 1.42 & 1.49 \\
\hline Community of Valencia & 1.16 & 1.37 & 1.62 & 1.29 & 1.53 & 1.42 \\
\hline Extremadura & 1.30 & 1.42 & 1.19 & 1.39 & 1.34 & 1.27 \\
\hline Galicia & 1.45 & 1.36 & 1.49 & 1.44 & 1.46 & 1.51 \\
\hline Madrid & 1.28 & 1.48 & 1.70 & 1.42 & 1.63 & 1.53 \\
\hline Murcia & 1.23 & 1.44 & 1.54 & 1.37 & 1.53 & 1.42 \\
\hline Navarre & 1.47 & 1.52 & 1.42 & 1.54 & 1.51 & 1.49 \\
\hline Basque Country & 1.47 & 1.21 & 1.43 & 1.38 & 1.35 & 1.49 \\
\hline Rioja & 1.15 & 1.73 & 1.33 & 1.48 & 1.57 & 1.27 \\
\hline Ceuta & 1.66 & 1.37 & 1.64 & 1.55 & 1.54 & 1.69 \\
\hline
\end{tabular}

Note: Data from National Health Survey from the National Institute of Statistics. Sample has been restricted to respondents aged 50 and over. 
Table A7. Descriptive statistics for total number of hospital admissions and length of stay over the last year (mean; median between parentheses; standard deviation between parentheses)

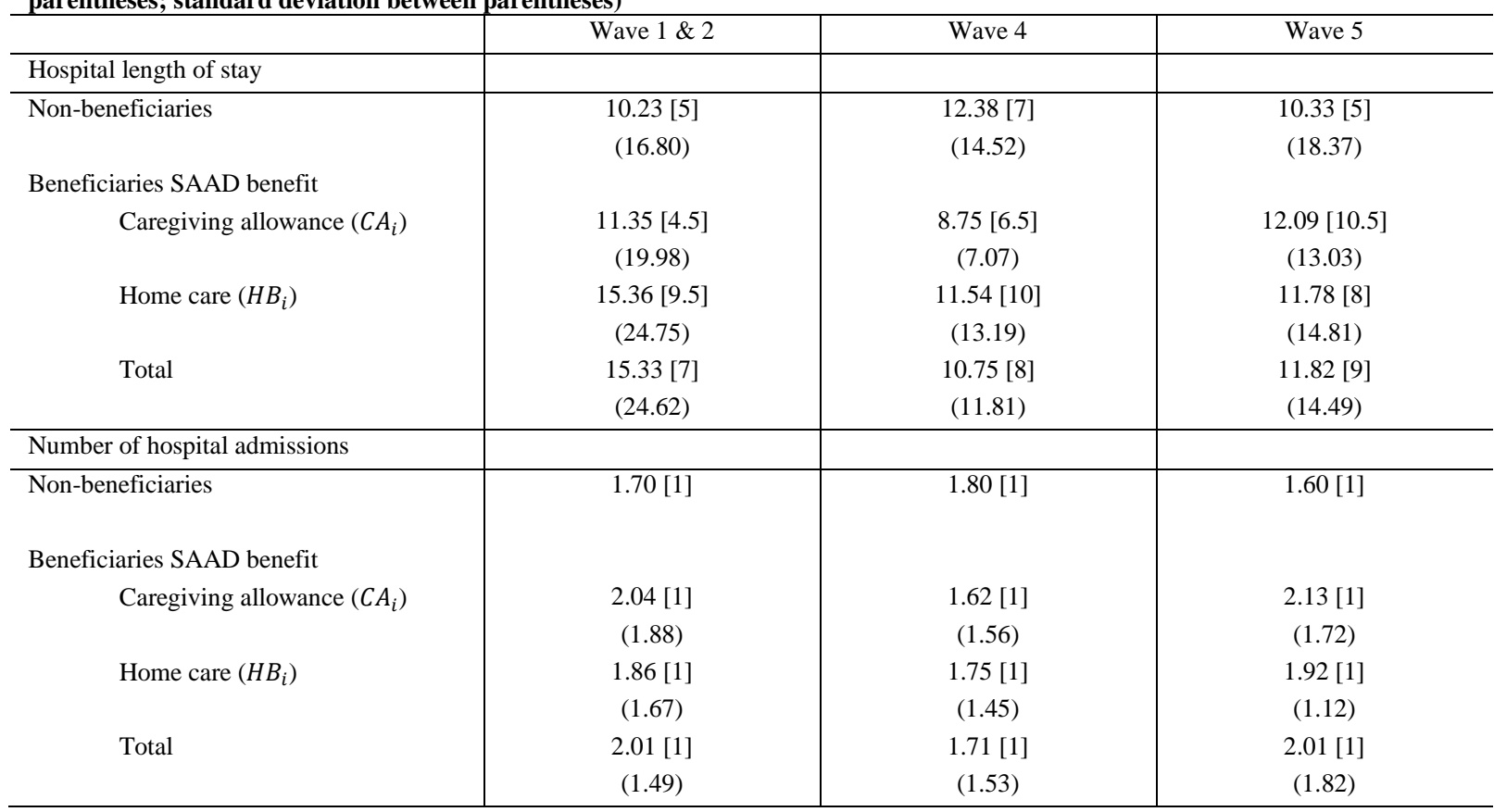

Source: SHARE, several years. $S A A D_{i}$ : binary variable representing the treatment group that takes the value 1 for individuals receiving LTC benefits (either caregiving allowances $\left(C A_{i}\right)$ or home care benefits $\left.\left(H B_{i}\right)\right)$. Total number of individuals hospitalized: 1,389 for nonbeneficiaries (Waves 1\&2: 418; Wave 4: 344; Wave 5: 627), 185 for $C B_{i}$ (Waves 1\&2: 65; Wave 4: 41; Wave 5; 79 ), 170 for $H B_{i}$ (Waves 1\&2: 85; Wave 4: 45; Wave 5: 40); 355 for total beneficiaries (Waves1\&2: 150; Wave 2: 86; Wave 5: 119). Total number of observations: 13,512 for non-beneficiaries, 751 for $C B_{i}, 503$ for $H B_{i}, 1,254$ for total beneficiaries.

Table A8. Descriptive statistics for explanatory variables

\begin{tabular}{|c|c|c|c|c|}
\hline & $C A_{i}$ & $H B_{i}$ & Any SAAD benefit & No SAAD benefit \\
\hline Male & 51.93 & 33.28 & 44.02 & 44.88 \\
\hline \multirow[t]{2}{*}{ Age } & 65.13 & 77.05 & 70.30 & 67.09 \\
\hline & (10.03) & $(10.83)$ & (12.01) & $(11.05)$ \\
\hline \multicolumn{5}{|l|}{ Marital status } \\
\hline Married/cohabiting & 72.97 & 58.54 & 66.51 & 77.72 \\
\hline Separated/divorced & 4.39 & 2.09 & 3.35 & 2.86 \\
\hline Single & 13.58 & 7.49 & 10.77 & 5.37 \\
\hline Widowed & 7.59 & 31.01 & 18.10 & 12.95 \\
\hline Missing marital status & 1.47 & 0.87 & 1.27 & 1.10 \\
\hline \multicolumn{5}{|l|}{ Education } \\
\hline No schooling & 25.97 & 31.71 & 28.31 & 18.62 \\
\hline Elementary & 52.46 & 42.16 & 48.72 & 53.97 \\
\hline High School & 6.79 & 5.75 & 6.22 & 9.31 \\
\hline College & 14.78 & 20.38 & 16.75 & 18.10 \\
\hline \multicolumn{5}{|l|}{ Self-reported health } \\
\hline Excellent & 0.80 & 0.35 & 0.64 & 3.36 \\
\hline Good & 3.33 & 2.26 & 2.87 & 13.89 \\
\hline Fair & 17.44 & 13.59 & 16.03 & 35.82 \\
\hline Poor & 78.43 & 83.80 & 80.46 & 46.93 \\
\hline \multicolumn{5}{|l|}{ Dependency degree } \\
\hline Katz0 & 69.77 & 49.83 & 62.04 & 89.25 \\
\hline Katz1 & 13.32 & 21.60 & 16.91 & 6.26 \\
\hline Katz2 & 7.46 & 11.15 & 9.09 & 2.05 \\
\hline Katz3 & 9.45 & 17.42 & 11.96 & 2.44 \\
\hline \multirow[t]{2}{*}{ Real wealth (€2011) } & 219,620 & 267,752 & 243,281 & 299,106 \\
\hline & $(592,726)$ & $(979,304)$ & $(799,507)$ & $(740,467)$ \\
\hline \multirow[t]{2}{*}{ Real income $(€ 2011)$} & 19,549 & 16,519 & $18,399.2$ & 21,792 \\
\hline & $(19,325)$ & $(18,262)$ & $(19,221)$ & $(26,805)$ \\
\hline $\mathrm{N}$ & 751 & 503 & 1,254 & 13,512 \\
\hline
\end{tabular}

CA: caregiving allowance. HB: home care benefits. Standard deviation between parentheses. The dependency degree is approximated using the Katz Index (Katz, 1983). The Katz Index determines functional status as a measurement of the ability to perform six daily living activities independently. We have computed this index using the information on daily living activities provided by SHARE. Respondents have been classified into four categories: Katz0 indicates that the individual performs all activities independently; Katz1 indicates that the individual performs four or five activities independently (which could be identified as a moderate degree of dependency); Katz2 indicates that the individual only performs two or three activities independently (severe dependency); Katz3 indicates that the individual needs help for all activities (or all but one), and should therefore be considered a major dependent.. 
Table A9. Hospital-related variables

\begin{tabular}{|c|c|c|c|c|c|}
\hline & 2004 & 2006 & 2007 & 2011 & 2013 \\
\hline Infection rate at hospital ${ }^{a}$ & 1.16 & 1.19 & 1.18 & 1.26 & 1.32 \\
\hline Number of public hospital beds per 1,000 inhabitants a & 2.22 & 2.15 & 2.30 & 2.42 & 2.53 \\
\hline Degree of satisfaction with public healthcare ${ }^{\text {a }}$ & 6.25 & 5.62 & 6.36 & 6.57 & 6.31 \\
\hline Public health expenditure per capita $(€ 2011)^{\mathrm{a}}$ & 1.152 & 1,333 & 1,390 & 1,392 & 1,248 \\
\hline Rate of medical hospital complications ${ }^{\mathrm{b}}$ & 3.37 & 3.60 & 3.60 & 4.31 & 4.38 \\
\hline
\end{tabular}

Appendix B. Instrumental Variables Support Information

Table B1. Percentage of votes for the socialist party in regional elections

\begin{tabular}{|c|c|c|c|c|c|}
\hline \multirow{2}{*}{ 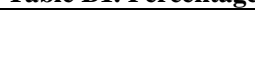 } & \multirow{2}{*}{$\begin{array}{c}\text { Wave } 1 \\
2004\end{array}$} & \multicolumn{2}{|c|}{ Wave 2} & \multirow{2}{*}{$\begin{array}{c}\text { Wave } 4 \\
2011\end{array}$} & \multirow{2}{*}{$\begin{array}{c}\text { Wave } 5 \\
2013\end{array}$} \\
\hline & & 2006 & 2007 & & \\
\hline Andalusia & 51.07 & 51.07 & 51.07 & 48.41 & 39.52 \\
\hline Aragón & 37.91 & 37.91 & 41.03 & 41.03 & 21.41 \\
\hline Asturias & 40.30 & 40.30 & 42.04 & 42.04 & 26.45 \\
\hline Balearic Isles & 24.60 & 24.60 & 31.75 & 31.75 & 18.94 \\
\hline Canary Islands & 25.50 & 25.50 & 34.72 & 34.72 & 19.96 \\
\hline Cantabria & 29.91 & 29.91 & 24.33 & 24.33 & 14.01 \\
\hline Community of León & 36.74 & 36.74 & 37.49 & 37.49 & 37.77 \\
\hline $\begin{array}{l}\text { Community of La } \\
\text { Mancha }\end{array}$ & 57.81 & 57.81 & 51.92 & 51.92 & 36.11 \\
\hline Catalonia & 31.16 & 31.16 & 27.38 & 18.32 & 14.43 \\
\hline $\begin{array}{l}\text { Community of } \\
\text { Valencia }\end{array}$ & 46.92 & 46.92 & 34.49 & 34.49 & 20.30 \\
\hline Extremadura & 51.62 & 51.62 & 52.90 & 52.90 & 41.50 \\
\hline Galicia & 22.20 & 33.64 & 33.64 & 31.02 & 20.61 \\
\hline Madrid & 33.46 & 33.46 & 33.47 & 33.47 & 25.44 \\
\hline Murcia & 34.03 & 34.03 & 31.81 & 31.81 & 23.96 \\
\hline Navarre & 21.14 & 21.14 & 22.40 & 22.40 & 13.43 \\
\hline Basque Country & 17.90 & 22.68 & 22.68 & 30.70 & 19.14 \\
\hline La Rioja & 38.29 & 38.29 & 40.47 & 40.47 & 26.70 \\
\hline Ceuta & 8.76 & 8.76 & 8.71 & 8.71 & 11.70 \\
\hline
\end{tabular}

Source: author's own work using http://www.congreso.es/consti/elecciones/autonomicas/

Aragón, Asturias, Balearic Isles, Canary Islands, Cantabria, Community of León, Community of La Mancha, Community of Valencia, Extremadura, Madrid, Murcia, Navarre, La Rioja, and Ceuta:

- Results from regional elections May 25, 2003 have been applied to Waves 1 and Wave 2 (2006).

- $\quad$ Results from regional elections May 27, 2007 have been applied to Wave 2 (2007) and Wave 4.

- $\quad$ Results from regional elections May 22, 2011 have been applied to Wave 5. Andalusia:

- $\quad$ Results from regional elections March 14, 2004 have been applied to Waves 1 and 2.

- $\quad$ Results from regional elections March 9, 2008 have been applied to Wave 4.

Catalonia

Results from regional election March 25, 2012 have been applied to Wave 5.

- Results from regional elections November 16, 2003 have been applied to Wave 1 and Wave 2 (only 2006).

- $\quad$ Results from regional elections November 1, 2006 have been applied to Wave 2 (only 2007).

- Results from regional elections November 28, 2010 have been applied to Wave 1 Basque Country Results from regional elections November 25, 2012 have been applied to Wave 5.

- $\quad$ Results from regional elections May 13, 2001 have been applied to Wave 1.

- Results from regional elections April 17, 2005 have been applied to Wave 2.

- Results from regional elections March 1, 2009 have been applied to Wave 4.

- Results from regional elections October 21, 2012 have been applied to Wave 5.

Galicia

- Results from regional elections October 21, 2001 have been applied to Wave 1.

- Results from regional elections June 19, 2005 have been applied to Wave 2.

- Results from regional elections March 1, 2009 have been applied to Wave 4.

- Results from regional elections October 21, 2012 have been applied to Wave 5 
Table B2. Coverage index of public home care

\begin{tabular}{lcc}
\hline & 2000 & 2002 \\
\hline Andalusia & 1.79 & 2.04 \\
Aragón & 2.52 & 2.44 \\
Asturias & 1.51 & 1.79 \\
Balearic Isles & 2.28 & 2.78 \\
Canary Islands & 1.9 & 1.88 \\
Cantabria & 1.51 & 1.55 \\
Community of León & 2.54 & 2.48 \\
Community of La & & \\
Mancha & 2.13 & 2.55 \\
Catalonia & 1.23 & 1.3 \\
Community of & & \\
Valencia & 0.78 & 2.16 \\
Extremadura & 4.69 & 4.86 \\
Galicia & 1.16 & 1.35 \\
Madrid & 1.98 & 1.89 \\
Murcia & 1.44 & 1.60 \\
Navarre & 3.33 & 3.02 \\
Basque Country & 2.3 & 2.85 \\
Rioja & 2.76 & 2.84 \\
Ceuta & 2.79 & 1.76 \\
\hline
\end{tabular}

Coverage index: ratio of number of home care beneficiaries divided by population aged 65 and over and multiplied by 100. Source: 'Las personas mayores en España’' (IMSERSO, 2000, 2002)

\section{Appendix C. Panel and Additional Estimates}

Table C1. Hurdle Poisson for number $\left(H N_{i}\right)$ and length of stay of hospital admissions $\left(H L S_{i}\right)$ without control function. Logit for the first hurdle; zero truncated Poisson for the second hurdle. Marginal effects are shown for the first hurdle; incidence rate ratio are shown for the second hurdle. Bootstrap with 100 repetitions. The first hurdle $\left(H_{i}\right)$ coincides for both hurdle Poisson models.

\begin{tabular}{|c|c|c|c|c|c|c|}
\hline & \multicolumn{3}{|c|}{$\begin{array}{c}C A_{i} \\
\text { Without control function } \\
\end{array}$} & \multicolumn{3}{|c|}{$\begin{array}{c}H B_{i} \\
\text { Without control function }\end{array}$} \\
\hline & $H_{i}$ & $H N_{i}$ & $\overline{H L S_{i}}$ & $H_{i}$ & $H N_{i}$ & $H L S_{i}$ \\
\hline \multicolumn{7}{|l|}{ A. Baseline } \\
\hline $\begin{array}{l}\text { SAAD } \\
\text { SAAD*POST }\end{array}$ & $\begin{array}{l}0.079 \text { *** } \\
(0.01) \\
-0.096 * * * \\
(0.01)\end{array}$ & $\begin{array}{l}1.109 * * \\
(0.02) \\
0.778 * * * \\
(0.03)\end{array}$ & $\begin{array}{l}0.912 * * * \\
(0.02) \\
0.776^{* * *} \\
(0.02)\end{array}$ & $\begin{array}{l}0.052 * * * \\
(0.00) \\
0.015 \\
(0.01)\end{array}$ & $\begin{array}{l}1.087 \\
(0.07) \\
0.874 * * * \\
(0.01)\end{array}$ & $\begin{array}{l}1.312^{* * *} \\
(0.00) \\
0.695 * * * \\
(0.01)\end{array}$ \\
\hline \multicolumn{7}{|l|}{ B. Coordination Plans } \\
\hline SAAD & $\begin{array}{l}0.085^{* * * *} \\
(0.01)\end{array}$ & $\begin{array}{l}1.815^{* * * *} \\
(0.18)\end{array}$ & $\begin{array}{l}0.847 * * * \\
(0.05)\end{array}$ & $\begin{array}{l}0.054 * * * \\
(0.00)\end{array}$ & $\begin{array}{l}1.058 \\
(0.08)\end{array}$ & $\begin{array}{l}1.239 * * * \\
(0.00)\end{array}$ \\
\hline SAAD*POST & $\begin{array}{l}-0.077 * * * \\
(0.01)\end{array}$ & $\begin{array}{l}0.903 * * * \\
(0.20)\end{array}$ & $\begin{array}{l}0.878^{* * *} \\
(0.04)\end{array}$ & $\begin{array}{l}0.016 \\
(0.00)\end{array}$ & $\begin{array}{l}0.948^{* *} \\
(0.02)\end{array}$ & $\begin{array}{l}0.801 * * * \\
(0.02)\end{array}$ \\
\hline Coordination & $\begin{array}{l}0.038 \\
(0.01)\end{array}$ & $\begin{array}{l}0.958 \\
(0.29)\end{array}$ & $\begin{array}{l}1.027 \\
(0.05)\end{array}$ & $\begin{array}{l}0.038 \\
(0.01)\end{array}$ & $\begin{array}{l}1.021 \\
(0.25)\end{array}$ & $\begin{array}{l}0.924 \\
(0.08)\end{array}$ \\
\hline Coordination* POST & $\begin{array}{l}-0.095^{* * *} \\
(0.02)\end{array}$ & $\begin{array}{l}1.154 \\
(0.33)\end{array}$ & $\begin{array}{l}1.102 \\
(0.05)\end{array}$ & $\begin{array}{l}-0.090^{* * *} \\
(0.01)\end{array}$ & $\begin{array}{l}1.009 \\
(0.25)\end{array}$ & $\begin{array}{l}0.129 \\
(0.05)\end{array}$ \\
\hline SAAD *Coord & $\begin{array}{l}-0.031 \\
(0.02)\end{array}$ & $\begin{array}{l}1.396 * * * \\
(0.30)\end{array}$ & $\begin{array}{l}1.091 \\
(0.10)\end{array}$ & $\begin{array}{l}-0.019 \\
(0.01)\end{array}$ & $\begin{array}{l}1.556 \\
(0.26)\end{array}$ & $\begin{array}{l}1.4296^{* * * *} \\
(0.04)\end{array}$ \\
\hline SAAD* Coord *POST & $\begin{array}{l}-0.117^{*} \\
(0.02)\end{array}$ & $\begin{array}{l}0.914 * * * \\
(0.00)\end{array}$ & $\begin{array}{l}1.187 \\
(0.10)\end{array}$ & $\begin{array}{l}-0.18 * * * \\
(0.01)\end{array}$ & $\begin{array}{l}0.843 * * * \\
(0.02)\end{array}$ & $\begin{array}{l}0.724 * * * \\
(0.10)\end{array}$ \\
\hline \multicolumn{7}{|l|}{ C. Effect of budgetary cuts } \\
\hline SAAD & $\begin{array}{l}0.078 * * * \\
(0.01)\end{array}$ & $\begin{array}{l}0.878 \\
(0.12)\end{array}$ & $\begin{array}{l}0.915^{* * * *} \\
(0.03)\end{array}$ & $\begin{array}{l}0.052 * * * \\
(0.00)\end{array}$ & $\begin{array}{l}1.078 \\
(0.05)\end{array}$ & $\begin{array}{l}1.333^{* * *} \\
(0.00)\end{array}$ \\
\hline SAAD*POST (2011\&2013) & $\begin{array}{l}-0.105^{*} \\
(0.02)\end{array}$ & $\begin{array}{l}0.906 \\
(0.65)\end{array}$ & $\begin{array}{l}0.924 * * * \\
(0.03)\end{array}$ & $\begin{array}{l}-0.029 \\
(0.05)\end{array}$ & $\begin{array}{l}0.598 \\
(0.90)\end{array}$ & $\begin{array}{l}0.847 \text { *** } \\
(0.22)\end{array}$ \\
\hline SAAD*POST (2013) & $\begin{array}{l}-0.289 \\
(1.51) \\
\end{array}$ & $\begin{array}{l}1.203 * * \\
(0.02) \\
\end{array}$ & $\begin{array}{l}1.347 * * \\
(0.50)\end{array}$ & $\begin{array}{l}0.657 \\
(1.12) \\
\end{array}$ & $\begin{array}{l}1.459 \text { *** } \\
(0.05)\end{array}$ & $\begin{array}{l}1.556 * * \\
(0.22)\end{array}$ \\
\hline $\mathrm{N}$ & 14,766 & 1,705 & 1,705 & 14,766 & 1,705 & 1,705 \\
\hline
\end{tabular}

SAAD: binary variable representing the treatment group that takes the value 1 for individuals receiving LTC benefits (either caregiving allowances $\left(C A_{i}\right)$ or home care benefits $\left.\left(H B_{i}\right)\right)$. $\mathrm{H}$ : having been hospitalized in the last 12 months. HN: number of hospitalizations in the last 12 months. HLS: number of days hospitalized during all hospitalizations in the last 12 months. POST: binary variable that takes the value 1 after the reform in the Spanish LTC system. Coord is a binary variable that takes the value 1 if there is a coordination program between healthcare and LTC care services in the region, and 0 otherwise.

Notes: Logit for the first hurdle; zero truncated Poisson for the second hurdle (two alternative dependent variables). Marginal effects are shown for the first hurdle; incidence rate ratios are shown for the second hurdle. For residuals we report the estimated coefficients. Bootstrap with 100 repetitions. The first hurdle $\left(H_{i}\right)$ coincides for both Poisson hurdle models.

Estimated coefficients for age, gender, marital status, level of education, self-reported health status, Katz Index, real income, real wealth, per capita public healthcare expenditure, number of public hospital beds per 1,000 inhabitants, satisfaction with the public healthcare system, infection rate at hospital, year and regional dummies are not shown. Standard deviations between parentheses. $* * *$ means significance at $1 \%$ level, ** at $5 \%$ level, * at $10 \%$ level. 
Table C2. Hurdle Poisson with control function for hospital admissions (logit for the first hurdle; zero-truncated Poisson for the second hurdle). Full Specification.

\begin{tabular}{|c|c|c|c|c|c|c|}
\hline & \multicolumn{3}{|c|}{$C A_{i}$} & \multicolumn{3}{|c|}{$H B_{i}$} \\
\hline & $H_{i}$ & $H N_{i}$ & $H L S_{i}$ & $H_{i}$ & $H N_{i}$ & $H L S_{i}$ \\
\hline Male & $\begin{array}{l}0.056 \\
(0.04)\end{array}$ & $\begin{array}{l}1.341 \text { *** } \\
(0.40)\end{array}$ & $\begin{array}{l}0.321 \text { *** } \\
(0.11)\end{array}$ & $\begin{array}{l}0.050 * * * \\
(0.02)\end{array}$ & $\begin{array}{l}0.454^{* * *} \\
(0.16)\end{array}$ & $\begin{array}{l}0.035 \\
(0.04)\end{array}$ \\
\hline Age & $\begin{array}{l}-0.001 \\
(0.00)\end{array}$ & $\begin{array}{l}-0.092^{* * *} \\
(0.04)\end{array}$ & $\begin{array}{l}-0.020 * * \\
(0.01)\end{array}$ & $\begin{array}{l}-0.002 \\
(0.00)\end{array}$ & $\begin{array}{l}-0.031 \\
(0.03)\end{array}$ & $\begin{array}{l}0.009 \\
(0.01)\end{array}$ \\
\hline Married/cohabiting & $\begin{array}{l}-0.006 \\
(0.01)\end{array}$ & $\begin{array}{l}0.082 \\
(0.12)\end{array}$ & $\begin{array}{l}0.282^{* * * *} \\
(0.03)\end{array}$ & $\begin{array}{l}-0.006 \\
(0.01)\end{array}$ & $\begin{array}{l}-0.242^{* *} \\
(0.11)\end{array}$ & $\begin{array}{l}0.151^{* * * *} \\
(0.03)\end{array}$ \\
\hline Separated/divorced & $\begin{array}{l}-0.001 \\
(0.03)\end{array}$ & $\begin{array}{l}0.292 \\
(0.32)\end{array}$ & $\begin{array}{l}0.017 \\
(0.09)\end{array}$ & $\begin{array}{l}-0.034 \\
(0.03)\end{array}$ & $\begin{array}{l}-0.509 \\
(0.33)\end{array}$ & $\begin{array}{l}-0.052 \\
(0.09)\end{array}$ \\
\hline Single & $\begin{array}{l}0.059 \\
(0.11)\end{array}$ & $\begin{array}{l}2.678^{* *} \\
(1.14)\end{array}$ & $\begin{array}{l}0.861^{* * *} \\
(0.31)\end{array}$ & $\begin{array}{l}-0.013 \\
(0.02)\end{array}$ & $\begin{array}{l}-0.293^{*} \\
(0.17)\end{array}$ & $\begin{array}{l}0.092^{* *} \\
(0.05)\end{array}$ \\
\hline Missing marital status & $\begin{array}{l}-0.083 \\
(0.10)\end{array}$ & $\begin{array}{l}-2.491 * * \\
(1.25)\end{array}$ & $\begin{array}{l}-0.283 \\
(0.31)\end{array}$ & $\begin{array}{l}-0.048 \\
(0.06)\end{array}$ & $\begin{array}{l}-0.377 \\
(0.96)\end{array}$ & $\begin{array}{l}0.422 * \\
(0.22)\end{array}$ \\
\hline No schooling & $\begin{array}{l}-0.022^{* *} \\
(0.01)\end{array}$ & $\begin{array}{l}0.141 \\
(0.12)\end{array}$ & $\begin{array}{l}0.111^{* * *} \\
(0.03)\end{array}$ & $\begin{array}{l}-0.018^{*} \\
(0.01)\end{array}$ & $\begin{array}{l}0.160 \\
(0.12)\end{array}$ & $\begin{array}{l}0.098^{* * * *} \\
(0.03)\end{array}$ \\
\hline Elementary education & $\begin{array}{l}-0.027 \\
(0.02)\end{array}$ & $\begin{array}{l}-0.528^{* *} \\
(0.22)\end{array}$ & $\begin{array}{l}-0.111^{*} \\
(0.06)\end{array}$ & $\begin{array}{l}-0.006 \\
(0.01)\end{array}$ & $\begin{array}{l}0.081 \\
(0.15)\end{array}$ & $\begin{array}{l}0.047 \\
(0.04)\end{array}$ \\
\hline Secondary education & $\begin{array}{l}-0.038 \\
(0.05)\end{array}$ & $\begin{array}{l}-1.567 * * * \\
(0.51)\end{array}$ & $\begin{array}{l}-0.424 * * * * \\
(0.14)\end{array}$ & $\begin{array}{l}-0.019 \\
(0.02)\end{array}$ & $\begin{array}{l}-0.364^{*} \\
(0.20)\end{array}$ & $\begin{array}{l}-0.067 \\
(0.05)\end{array}$ \\
\hline Health status: excellent & $\begin{array}{l}-0.147^{* * *} \\
(0.03)\end{array}$ & $\begin{array}{l}-1.176^{* * *} \\
(0.33)\end{array}$ & $\begin{array}{l}-1.094 * * * \\
(0.16)\end{array}$ & $\begin{array}{l}-0.171 \text { *** } \\
(0.03)\end{array}$ & $\begin{array}{l}-1.192 * * * \\
(0.33)\end{array}$ & $\begin{array}{l}-1.057 * * * \\
(0.16)\end{array}$ \\
\hline Health status: good & $\begin{array}{l}-0.151^{* * *} \\
(0.01)\end{array}$ & $\begin{array}{l}-2.001 * * \\
(0.99)\end{array}$ & $\begin{array}{l}-0.843 * * * \\
(0.07)\end{array}$ & $\begin{array}{l}-0.157 \text { *** } \\
(0.01)\end{array}$ & $\begin{array}{l}-2.029 * * \\
(0.99)\end{array}$ & $\begin{array}{l}-0.827 * * * * \\
(0.07)\end{array}$ \\
\hline Health status: fair & $\begin{array}{l}-0.094 * * * \\
(0.01)\end{array}$ & $\begin{array}{l}-0.336 * * * \\
(0.10)\end{array}$ & $\begin{array}{l}-0.350^{\text {**** }} \\
(0.03)\end{array}$ & $\begin{array}{l}-0.080^{\text {**** }} \\
(0.01)\end{array}$ & $\begin{array}{l}-0.346^{* * *} \\
(0.10)\end{array}$ & $\begin{array}{l}-0.337 * * * \\
(0.03)\end{array}$ \\
\hline Dependency: Katz1 & $\begin{array}{l}0.137 \\
(0.11)\end{array}$ & $\begin{array}{l}3.011^{* * * *} \\
(1.13)\end{array}$ & $\begin{array}{l}1.159^{* * *} \\
(0.31)\end{array}$ & $\begin{array}{l}-0.040 \\
(0.10)\end{array}$ & $\begin{array}{l}-0.365 \\
(1.10)\end{array}$ & $\begin{array}{l}0.902 * * * \\
(0.30)\end{array}$ \\
\hline Dependency: Katz2 & $\begin{array}{l}0.233 \\
(0.16)\end{array}$ & $\begin{array}{l}4.349 * * \\
(1.71)\end{array}$ & $\begin{array}{l}0.773 \\
(0.47)\end{array}$ & $\begin{array}{l}-0.081 \\
(0.19)\end{array}$ & $\begin{array}{l}-0.957 \\
(1.99)\end{array}$ & $\begin{array}{l}0.696 \\
(0.53)\end{array}$ \\
\hline Dependency: Katz3 & $\begin{array}{l}0.223 \\
(0.18)\end{array}$ & $5.249 * * *$ & $\begin{array}{l}1.719^{* * * *} \\
(0.53)\end{array}$ & $\begin{array}{l}-0.159 \\
(0.25)\end{array}$ & $\begin{array}{l}-1.330 \\
(0.85)\end{array}$ & $\begin{array}{l}1.405^{*} \\
(0.72)\end{array}$ \\
\hline $\begin{array}{l}\text { Real wealth } \\
(€ 1,000,000)\end{array}$ & $\begin{array}{l}-0.001 \\
(0.01)\end{array}$ & $\begin{array}{l}-0.438^{* * * *} \\
(0.12)\end{array}$ & $\begin{array}{l}-0.018 \\
(0.02)\end{array}$ & $\begin{array}{l}0.009 \\
(0.01)\end{array}$ & $\begin{array}{l}-0.157 \\
(0.11)\end{array}$ & $\begin{array}{l}0.041^{* *} \\
(0.02)\end{array}$ \\
\hline Real income $(€ 1,000)$ & $\begin{array}{l}-0.214 \\
(0.36)\end{array}$ & $\begin{array}{l}12.440^{* * * *} \\
(3.93)\end{array}$ & $\begin{array}{l}-7.731 * * * \\
(1.12)\end{array}$ & $\begin{array}{l}0.130 \\
(0.18)\end{array}$ & $\begin{array}{l}-2.212 \\
(2.24)\end{array}$ & $\begin{array}{l}-6.251 * * * \\
(0.66)\end{array}$ \\
\hline $\begin{array}{l}\text { Public healthcare } \\
\text { expenditure. }(€ 1,000)\end{array}$ & $\begin{array}{l}-0.083 \\
(0.08)\end{array}$ & $\begin{array}{l}-2.025^{* *} \\
(0.91)\end{array}$ & $\begin{array}{l}0.572 * * * \\
(0.22)\end{array}$ & $\begin{array}{l}-0.076 \\
(0.08)\end{array}$ & $\begin{array}{l}-1.886^{* *} \\
(0.89)\end{array}$ & $\begin{array}{l}0.328 * * * \\
(0.22)\end{array}$ \\
\hline Infection rate & $\begin{array}{l}0.011 \\
(0.04)\end{array}$ & $\begin{array}{l}-0.997 * * \\
(0.43)\end{array}$ & $\begin{array}{l}-0.387 * * * \\
(0.12)\end{array}$ & $\begin{array}{l}0.024 \\
(0.04)\end{array}$ & $\begin{array}{l}-0.918^{* *} \\
(0.46)\end{array}$ & $\begin{array}{l}-0.440^{* * *} \\
(0.13)\end{array}$ \\
\hline $\begin{array}{l}\text { Satisfaction with public } \\
\text { healthcare system }\end{array}$ & $\begin{array}{l}0.001 \\
(0.00)\end{array}$ & $\begin{array}{l}0.004 \\
(0.01)\end{array}$ & $\begin{array}{l}-0.014 * * * \\
(0.00)\end{array}$ & $\begin{array}{l}0.001 \\
(0.00)\end{array}$ & $\begin{array}{l}0.002 \\
(0.01)\end{array}$ & $\begin{array}{l}-0.015^{* * * *} \\
(0.00)\end{array}$ \\
\hline $\begin{array}{l}\text { Public beds }(1,000 \\
\text { inhabitants }) \\
\text { Constant }\end{array}$ & $\begin{array}{l}0.005 \\
(0.02)\end{array}$ & $\begin{array}{l}-0.045 \\
(0.18) \\
11.302^{* * * *} \\
(3.14)\end{array}$ & $\begin{array}{l}0.021 \\
(0.05) \\
1.294 \\
(0.85)\end{array}$ & $\begin{array}{l}0.000 \\
(0.02)\end{array}$ & $\begin{array}{l}-0.020 \\
(0.18) \\
4.892 * * \\
(1.98)\end{array}$ & $\begin{array}{l}0.007 \\
(0.05) \\
-0.413 \\
(0.50)\end{array}$ \\
\hline $\mathrm{N}$ & 14,766 & 1,705 & 1,705 & 14,766 & 1,705 & 1,705 \\
\hline
\end{tabular}

Note: H: having been hospitalized in the last 12 months. HN: number of hospitalizations in the last 12 months. HLS: length of stay at hospital during all hospitalizations in the last 12 months. CA: caregiving allowance. HB: home care benefits. The dependency degree is approximated using the Katz Index (Katz, 1983). The Katz Index determines functional status as a measurement of the ability to perform six daily living activities independently. We have computed this index using the information on daily living activities provided by SHARE. Respondents have been classified into four categories: Katz0 indicates that the individual performs all activities independently; Katz1 indicates that the individual performs four or five activities independently (which could be identified as a moderate degree of dependency); Katz2 indicates that the individual only performs two or three activities independently (severe dependency); Katz3 indicates that the individual needs help for all activities (or all but one), and should therefore be considered a major dependent. Logit for the first hurdle; zero truncated Poisson for the second hurdle (two alternative dependent variables). Marginal effects are shown for the first hurdle; incidence rate ratios are shown for the second hurdle. For residuals, we report the estimated coefficients. Bootstrap with 100 repetitions. The first hurdle $\left(H_{i}\right)$ coincides for both Poisson hurdle models. Year and regional dummies are not shown. Standard deviations between parentheses. *** means significance at $1 \%$ level, ** at $5 \%$ level, * at $10 \%$ level. F-test of residuals is distributed according to $\mathrm{F}(2,14726)$ for the logit model, $\mathrm{F}(2,1665)$ 
Table C3. Panel data estimates

\begin{tabular}{|c|c|c|c|c|c|c|}
\hline & \multicolumn{3}{|c|}{$C A_{i}$} & \multicolumn{3}{|c|}{$H B_{i}$} \\
\hline & $H_{i}$ & $H N_{i}$ & $H L S_{i}$ & $H_{i}$ & $H N_{i}$ & $H L S_{i}$ \\
\hline \multicolumn{7}{|l|}{ A. Baseline } \\
\hline $\begin{array}{l}\text { SAAD } \\
\text { SAAD*POST }\end{array}$ & $\begin{array}{l}0.053 * * * \\
(0.01) \\
-0.078 * * * \\
(0.01) \\
\end{array}$ & $\begin{array}{l}1.012 * * \\
(0.02) \\
0.712 * * * \\
(0.04) \\
\end{array}$ & $\begin{array}{l}0.780 * * * \\
(0.03) \\
0.705 * * * \\
(0.05) \\
\end{array}$ & $\begin{array}{l}0.041 * * * \\
(0.01) \\
0.007 \\
(0.01) \\
\end{array}$ & $\begin{array}{l}0.957 \\
(0.07) \\
0.789 * * * \\
(0.02) \\
\end{array}$ & $\begin{array}{l}1.175 * * * \\
(0.02) \\
0.612 * * * \\
(0.03) \\
\end{array}$ \\
\hline \multicolumn{7}{|l|}{ B. Coordination Plans } \\
\hline SAAD & $\begin{array}{l}0.078 \text { *** } \\
(0.01)\end{array}$ & $\begin{array}{l}1.756^{* * * *} \\
(0.15)\end{array}$ & $\begin{array}{l}0.786^{* * * *} \\
(0.05)\end{array}$ & $\begin{array}{l}0.047 * * * \\
(0.00)\end{array}$ & $\begin{array}{l}1.041 \\
(0.08)\end{array}$ & $\begin{array}{l}1.165 \text { *** } \\
(0.00)\end{array}$ \\
\hline SAAD*POST & $\begin{array}{l}-0.070^{* * * *} \\
(0.01)\end{array}$ & $\begin{array}{l}0.847 \text { *** } \\
(0.17)\end{array}$ & $\begin{array}{l}0.801 \text { *** } \\
(0.04)\end{array}$ & $\begin{array}{l}0.03 \\
(0.00)\end{array}$ & $\begin{array}{l}0.874 * * \\
(0.02)\end{array}$ & $\begin{array}{l}0.733 * * * \\
(0.02)\end{array}$ \\
\hline Coordination & $\begin{array}{l}0.031 \\
(0.01)\end{array}$ & $\begin{array}{l}0.887 \\
(0.25)\end{array}$ & $\begin{array}{l}0.965 \\
(0.04)\end{array}$ & $\begin{array}{l}0.029 \\
(0.01)\end{array}$ & $\begin{array}{l}0.947 \\
(0.20)\end{array}$ & $\begin{array}{l}0.9847 \\
(0.06)\end{array}$ \\
\hline Coordination* POST & $\begin{array}{l}-0.084 * * * \\
(0.02)\end{array}$ & $\begin{array}{l}1.113 \\
(0.27)\end{array}$ & $\begin{array}{l}0.924 \\
(0.04)\end{array}$ & $\begin{array}{l}-0.082 * * * \\
(0.01)\end{array}$ & $\begin{array}{l}0.941 \\
(0.18)\end{array}$ & $\begin{array}{l}0.086 \\
(0.04)\end{array}$ \\
\hline SAAD *Coord & $\begin{array}{l}-0.024 \\
(0.02)\end{array}$ & $\begin{array}{l}1.302 * * * \\
(0.21)\end{array}$ & $\begin{array}{l}0.965 \\
(0.7)\end{array}$ & $\begin{array}{l}-0.015 \\
(0.01)\end{array}$ & $\begin{array}{l}1.441 \\
(0.23)\end{array}$ & $\begin{array}{l}1.372^{* * * *} \\
(0.04)\end{array}$ \\
\hline SAAD* Coord *POST & $\begin{array}{l}-0.101 \text { *** } \\
(0.01)\end{array}$ & $\begin{array}{l}0.879 \text { *** } \\
(0.00)\end{array}$ & $\begin{array}{l}1.104 \\
(0.09)\end{array}$ & $\begin{array}{l}-0.164 * * * \\
(0.01)\end{array}$ & $\begin{array}{l}0.775 \text { *** } \\
(0.02)\end{array}$ & $\begin{array}{l}0.657 \text { **** } \\
(0.08)\end{array}$ \\
\hline \multicolumn{7}{|l|}{ C. Effect of budgetary cuts } \\
\hline SAAD & $\begin{array}{l}0.068 \text { *** } \\
(0.01)\end{array}$ & $\begin{array}{l}0.814 \\
(0.10)\end{array}$ & $\begin{array}{l}0.853 \text { *** } \\
(0.03)\end{array}$ & $\begin{array}{l}0.041 * * * \\
(0.00)\end{array}$ & $\begin{array}{l}1.001 \\
(0.04)\end{array}$ & $\begin{array}{l}1.275^{* * * *} \\
(0.00)\end{array}$ \\
\hline SAAD*POST (2011\&2013) & $\begin{array}{l}-0.095^{*} \\
(0.02)\end{array}$ & $\begin{array}{l}0.825 \\
(0.57)\end{array}$ & $\begin{array}{l}0.874 \text { *** } \\
(0.02)\end{array}$ & $\begin{array}{l}-0.020 \\
(0.05)\end{array}$ & $\begin{array}{l}0.505 \\
(0.88)\end{array}$ & $\begin{array}{l}0.812 \text { *** } \\
(0.18)\end{array}$ \\
\hline SAAD*POST (2013) & $\begin{array}{l}-0.214 \\
(1.09)\end{array}$ & $\begin{array}{l}1.117 * * * \\
(0.00)\end{array}$ & $\begin{array}{l}1.286^{* * *} \\
(0.41)\end{array}$ & $\begin{array}{l}0.589 \\
(1.01)\end{array}$ & $\begin{array}{l}1.326^{* * * *} \\
(0.05)\end{array}$ & $\begin{array}{l}1.465^{* *} \\
(0.15)\end{array}$ \\
\hline $\mathrm{N}$ & 5,647 & 650 & 650 & 5,647 & 650 & 650 \\
\hline
\end{tabular}

Note: H refers to having been hospitalized in the last 12 months. HN: number of hospitalizations in the last 12 months. HLS: length of stay at hospital during all hospitalizations in the last 12 months. $S A A D_{i}$ : binary variable representing the treatment group that takes the value 1 for individuals receiving LTC benefits (either caregiving allowances $\left(C A_{i}\right)$ or home care benefits $\left(H B_{i}\right)$ ). POST: binary variable that takes the value 1 after the reform in the Spanish LTC system. Fixed effects logit for the first hurdle and fixed effects (H) and truncated Poisson for the second hurdle (HN and HLS). Marginal effects are shown for the first hurdle; incidence rate ratios are shown for the second hurdle. Estimated coefficients for age, gender, marital status, self-reported health status, Katz Index, real income, real wealth, per capita public healthcare expenditure, number of public hospital beds per 1,000 inhabitants, satisfaction with the public healthcare system, infection rate at hospital, year and regional dummies are not shown. Standard deviations between parentheses. *** means significance at $1 \%$ level, $* *$ at $5 \%$ level, * at $10 \%$ level 


\section{Appendix D. Mechanisms and falsification test}

Table D1. Descriptive statistics for mechanism variables

\begin{tabular}{|c|c|c|c|c|}
\hline & $C A_{i}$ & $H B_{i}$ & $\begin{array}{c}\text { Any SAAD } \\
\text { benefit }\end{array}$ & $\begin{array}{c}\text { No SAAD } \\
\text { benefit }\end{array}$ \\
\hline Depressed & 53.00 & 58.36 & 54.86 & 35.02 \\
\hline Would prefer to be dead & 18.64 & 20.56 & 19.38 & 7.48 \\
\hline Lives alone & 10.52 & 22.82 & 16.27 & 11.60 \\
\hline Adapted house & 4.13 & 6.45 & 5.18 & 2.78 \\
\hline Has visited GP in the last year & 42.48 & 53.48 & 47.37 & 38.97 \\
\hline \multirow[t]{2}{*}{ Number of visits to GP } & 8.73 & 12.63 & 10.66 & 6.72 \\
\hline & $(10.94)$ & $(16.40)$ & $(14.09)$ & $(8.69)$ \\
\hline Has visited a dentist in the last year & 14.38 & 12.19 & 13.79 & 18.66 \\
\hline Has ever been diagnosed with cataracts & 10.51 & 20.21 & 14.83 & 8.59 \\
\hline Surgery: Cataracts & 0.13 & 0.35 & 0.24 & 0.24 \\
\hline \multicolumn{5}{|l|}{ Household able to make ends meet } \\
\hline With great difficulty & 22.90 & 18.82 & 21.29 & 14.56 \\
\hline With some difficulty & 37.82 & 39.37 & 37.88 & 35.11 \\
\hline Fairly easily & 26.23 & 31.01 & 28.71 & 33.88 \\
\hline Easily & 13.05 & 10.80 & 12.12 & 16.45 \\
\hline $\mathrm{N}$ & 751 & 503 & 1,254 & 13,512 \\
\hline
\end{tabular}

CA: caregiving allowance. HB: home care benefits. $S A A D_{i}$ : binary variable that takes the value 1 for individuals receiving public LTC subsidies (both caregiving allowances $\left(C A_{i}\right)$ or home care support $\left(H B_{i}\right)$ ). Standard deviation is depicted in parentheses for continuous variables. Note: 5,860 individuals have visited their GP in the last year: 319 receiving $C A, 307$ receiving $H B$, 626 receiving any SAAD benefit, 5,234 not receiving SAAD benefit.

Table D2. Visits to GP. Logit for the first hurdle; zero truncated Poisson for the second hurdle. Marginal effects are shown for the first hurdle; incidence rate ratio is shown for the second hurdle. Bootstrap after 100 repetitions. Using IV for SAAD and SAAD*POST.

\begin{tabular}{|c|c|c|c|c|}
\hline & \multicolumn{2}{|r|}{$C A_{i}$} & \multicolumn{2}{|r|}{$H B_{i}$} \\
\hline & Has visited $G P_{i}$ & Number of GP visits ${ }_{i}$ & Has visited $G P_{i}$ & Number of GP visits $_{i}$ \\
\hline SAAD & $\begin{array}{l}0.123^{* * *} * \\
(0.04)\end{array}$ & $\begin{array}{l}1.161 \text { *** } \\
(0.03)\end{array}$ & $\begin{array}{l}0.062 * \\
(0.03)\end{array}$ & $\begin{array}{l}1.279 \text { *** } \\
(0.02)\end{array}$ \\
\hline SAAD*POST & $\begin{array}{l}0.088 \\
(0.07)\end{array}$ & $\begin{array}{l}1.074 * * \\
(0.02)\end{array}$ & $\begin{array}{l}-0.008 \\
(0.06)\end{array}$ & $\begin{array}{l}1.070^{* *} \\
(0.02)\end{array}$ \\
\hline Chi-square (38) & 694.76 & $8,379.23$ & 685.65 & $8,510.51$ \\
\hline $\mathrm{p}$-value & $(0.000)$ & $(0.000)$ & $(0.000)$ & $(0.000)$ \\
\hline $\mathrm{N}$ & 14,766 & 5,860 & 14,766 & 5,860 \\
\hline
\end{tabular}

$S A A D_{i}$ : binary variable representing the treatment group that takes the value 1 for individuals receiving LTC benefits (either caregiving allowances $\left(C A_{i}\right)$ or home care benefits $\left.\left(H B_{i}\right)\right)$. POST: binary variable that takes the value 1 after the reform in the Spanish LTC system. GP: general practitioner

Notes: Logit for the first hurdle; zero truncated Poisson for the second hurdle (two alternative dependent variables). Marginal effects are shown for the first hurdle; incidence rate ratios are shown for the second hurdle. For residuals, we report the estimated coefficients. Bootstrap with 100 repetitions. The first hurdle $\left(H_{i}\right)$ coincides for both hurdle Poisson models. Estimated coefficients for age, gender, marital status, level of education, self-reported health status, Katz Index, real income, real wealth, year and regional dummies are not shown. Standard deviation between parentheses. $* * *$ means significance at $1 \%$ level, ** at $5 \%$ level, * at $10 \%$ level. 
Table D3. Probit for the probability of being depressed, would prefer to be dead, living alone, and living in an adapted household. Marginal effects. Bootstrap after 100 repetitions. Using IV for SAAD and SAAD*POST.

\begin{tabular}{|c|c|c|c|c|c|c|c|c|}
\hline & \multicolumn{4}{|c|}{$C A_{i}$} & \multicolumn{4}{|c|}{$H B_{i}$} \\
\hline & Depressed $_{i}$ & Dead $_{i}$ & Alone $_{i}$ & Adapted $_{i}$ & Depressed $_{i}$ & Dead $_{i}$ & Alone $_{i}$ & Adapted $_{i}$ \\
\hline $\begin{array}{l}\text { SAAD } \\
\text { SAAD*POST }\end{array}$ & $\begin{array}{l}0.163 * * * \\
(0.03) \\
-0.025 * * * \\
(0.00) \\
\end{array}$ & $\begin{array}{l}0.095 * * * \\
(0.02) \\
-0.079 * * * \\
(0.02) \\
\end{array}$ & $\begin{array}{l}0.008 \\
(0.01) \\
-0.074 * * * \\
(0.00) \\
\end{array}$ & $\begin{array}{l}0.009 \\
(0.01) \\
0.001 \\
(0.01) \\
\end{array}$ & $\begin{array}{l}0.095^{* * * *} \\
(0.03) \\
0.032 \\
(0.04) \\
\end{array}$ & $\begin{array}{l}0.086 * * * \\
(0.02) \\
-0.054 * * * \\
(0.01) \\
\end{array}$ & $\begin{array}{l}0.034 * * * \\
(0.00) \\
-0.026 * * * \\
(0.00) \\
\end{array}$ & $\begin{array}{l}0.007 \\
(0.01) \\
0.020^{* * * *} \\
(0.00)\end{array}$ \\
\hline $\begin{array}{l}\text { Chi-square (32) } \\
\text { p-value } \\
\mathrm{N}\end{array}$ & $\begin{array}{l}1449.44 \\
(0.000) \\
14,766 \\
\end{array}$ & $\begin{array}{l}699.20 \\
(0.000) \\
14,766 \\
\end{array}$ & $\begin{array}{l}4366.07 \\
(0.000) \\
14,766 \\
\end{array}$ & $\begin{array}{l}335.93 \\
(0.000) \\
14,766 \\
\end{array}$ & $\begin{array}{l}1416.48 \\
(0.000) \\
14,766 \\
\end{array}$ & $\begin{array}{l}656.47 \\
(0.000) \\
14,766 \\
\end{array}$ & $\begin{array}{l}4365.06 \\
(0.000) \\
14,766 \\
\end{array}$ & $\begin{array}{l}343.43 \\
(0.000) \\
14,766 \\
\end{array}$ \\
\hline
\end{tabular}

$S A A D_{i}$ : binary variable representing the treatment group that takes the value 1 for individuals receiving LTC benefits (either caregiving allowances $\left(C A_{i c t}\right)$ or home care benefits $\left(H B_{i}\right)$ ). POST: binary variable that takes the value 1 after the reform in the Spanish LTC system. Dead: binary variable that takes the value 1 if the individual has reported preferring to be dead, and 0 otherwise. Depressed: binary variable that takes the value 1 if the individual has reported feeling depressed, and 0 otherwise. Alone: binary variable that takes the value 1 if the individual lives alone ( 0 otherwise). Adapted house: binary variable that takes the value 1 if the household has special features catering for persons with physical impairments or health problems, and 0 otherwise.

Note: Estimated coefficients for age, gender, marital status, level of education, real income, real wealth, year and regional dummies are not shown. Standard deviation between parentheses. *** means significance at $1 \%$ level, ** at $5 \%$ level, $*$ at $10 \%$ level.

Table D4. Effects of SAAD on Household Finances. Marginal effects. Bootstrap after 100 repetitions. Using IV for SAAD and SAAD*POST.

\begin{tabular}{|c|c|c|c|c|c|c|c|c|}
\hline & \multicolumn{4}{|c|}{$C A_{i}$} & \multicolumn{4}{|c|}{$H B_{i}$} \\
\hline & \multicolumn{4}{|c|}{ Household able to make ends meet } & \multicolumn{4}{|c|}{ Household able to make ends meet } \\
\hline & Great dif & Difficulty $_{i}$ & Fairly easily $_{i}$ & Easily $_{i}$ & Great dif $f_{i}$ & Difficulty $_{i}$ & Fairly easily $_{i}$ & Easily $_{i}$ \\
\hline \multirow[t]{2}{*}{ SAAD } & -0.023 & 0.005 & 0.011 & 0.025 & $0.042 * *$ & 0.006 & -0.017 & $-0.064 * * *$ \\
\hline & $(0.040)$ & $(0.031)$ & $(0.030)$ & $(0.035)$ & $(0.018$ & $(0.025)$ & $(0.025)$ & $(0.019)$ \\
\hline \multirow[t]{2}{*}{ SAAD*POST } & $-0.064 * *$ & $-0.044 *$ & $0.083 * * *$ & 0.010 & 0.041 & $0.160 * * *$ & $-0.091 *$ & $-0.071 *$ \\
\hline & $(0.025)$ & $(0.016)$ & $(0.026)$ & $(0.04)$ & $(0.037)$ & $(0.05)$ & $(0.05)$ & $(0.039)$ \\
\hline Chi-square (32) & 18.725 & 21.417 & 6.32 & 55.46 & 10.633 & 16.548 & 2.517 & 39.803 \\
\hline $\mathrm{p}$-value & $(0.000)$ & $(0.000)$ & $(0.000)$ & $(0.000)$ & $(0.000)$ & $(0.000)$ & $(0.039)$ & $(0.000)$ \\
\hline $\mathrm{N}$ & 14,766 & 14,766 & 14,766 & 14,766 & 14,766 & 14,766 & 14,766 & 14,766 \\
\hline
\end{tabular}

$S A A D_{i}$ : binary variable representing the treatment group that takes the value 1 for individuals receiving LTC benefits (either caregiving allowances $\left(C A_{i}\right)$ or home care benefits $\left.\left(H B_{i}\right)\right)$. POST: binary variable that takes the value 1 after the reform in the Spanish LTC system. Note: Estimated coefficients for age, gender, marital status, level of education, real income, real wealth, year and regional dummies are not shown. Standard deviation between parentheses. *** means significance at $1 \%$ level, $* *$ at $5 \%$ level, $*$ at $10 \%$ level

Table D5. Effects of SAAD on Dental Care

\begin{tabular}{|c|c|c|c|c|}
\hline & \multicolumn{2}{|r|}{$C A_{i}$} & \multicolumn{2}{|r|}{$H B_{i}$} \\
\hline & Dentist $_{i}$ & Cataract surgery $y_{i}$ & Dentist $_{i}$ & Cataract surgery $y_{i}$ \\
\hline SAAD & $\begin{array}{l}-0.077 * * \\
(0.032)\end{array}$ & $\begin{array}{l}-0.126^{* * * *} \\
(0.023)\end{array}$ & $\begin{array}{l}0.020 \\
(0.029)\end{array}$ & $\begin{array}{l}-0.021 \\
(0.018)\end{array}$ \\
\hline SAAD*POST & $\begin{array}{l}0.021 \\
(0.028)\end{array}$ & $\begin{array}{l}0.078^{*} \\
(0.055)\end{array}$ & $\begin{array}{l}-0.020 \\
(0.033)\end{array}$ & $\begin{array}{l}0.020 \\
(0.036)\end{array}$ \\
\hline $\begin{array}{l}\text { Chi-square (38) } \\
\text { p-value }\end{array}$ & $\begin{array}{l}37.881 \\
(0.000)\end{array}$ & $\begin{array}{l}9.792 \\
(0.000) \\
\end{array}$ & $\begin{array}{l}25.790 \\
(0.000) \\
\end{array}$ & $\begin{array}{l}17.505 \\
(0.000)\end{array}$ \\
\hline $\mathrm{N}$ & 14,766 & 1,392 & 14,766 & 1,392 \\
\hline
\end{tabular}

$S A A D_{i}$ : binary variable representing the treatment group that takes the value 1 for individuals receiving LTC benefits (either caregiving allowances $\left(C A_{i}\right)$ or home care benefits $\left.\left(H B_{i}\right)\right)$. POST: binary variable that takes the value 1 after the reform in the Spanish LTC system. Dentist: binary variable that takes the value 1 if the individual has visited the dentist in the last year. Cataract surgery: binary variable that takes the value 1 if the individual has undergone cataract surgery. Regressions for cataract surgery have been performed on the subsample diagnosed with cataracts. 